\title{
MICROSTRUCTURAL CONSTRAINTS ON COMPLEX THERMAL HISTORIES OF REFRACTORY CAI-LIKE OBJECTS IN AN AMOEBOID OLIVINE AGGREGATE FROM THE ALHA77307 CO3.0 CHONDRITE
}

\author{
JANGMI HAN $^{\mathrm{a}, *}$ AND ADRIAN J. BREARLEY ${ }^{\mathrm{a}}$ \\ ${ }^{a}$ Department of Earth and Planetary Sciences, University of New Mexico, Albuquerque, NM \\ 87131, USA. \\ *Corresponding author. Present address: Lunar and Planetary Institute, 3600 Bay Area \\ Boulevard, Houston, TX 77058, USA; NASA Johnson Space Center, 2101 NASA Parkway, \\ Houston, TX 77058, USA. \\ Email address: jangmi.han@nasa.gov (J. Han), brearley@unm.edu (A. J. Brearley). \\ Submitted to Geochimica et Cosmochimica Acta \\ January 2014
}




\section{ABSTRACT}

We have carried out a FIB/TEM study of refractory CAI-like objects in one AOA from the ALHA77307 CO3.0 chondrite. The CAI-like objects in the AOA consist of a zoned sequence with a spinel-rich core through an intergrowth layer of spinel and Al-Ti-rich diopside to a diopside rim. The spinel-rich core consists of polycrystalline aggregates of spinel and \pm minor melilite showing equilibrated grain boundary textures. The intergrowth layer contains finegrained diopside and spinel with minor anorthite with highly curved and embayed grain boundaries. The diopside rim consists of polycrystalline aggregates of diopside. The compositions of pyroxene change significantly outward from Al-Ti-rich diopside in contact with the spinel-rich core to Al-Ti-poor diopside next to the surrounding olivine of the AOA. Overall microstructural and chemical characteristics suggest that the spinel-rich core formed under equilibrium conditions whereas the intergrowth layer is the result of reactions that occurred under conditions that departed significantly from equilibrium. The remarkable changes in formation conditions of the CAI-like objects may have been achieved by transport and injection of refractory objects into a region of a partially-condensed, Ca,Ti-saturated gas which reacted with spinel and melilite to form Al-Ti-rich diopside.

Crystallographically-oriented $\mathrm{TiO}_{2}$ nanoparticles decorate the grain boundaries between spinel grains and between spinel and Al-Ti-rich diopside grains. During the disequilibrium backreaction of spinel with a partially-condensed, $\mathrm{Ca}$,Ti-saturated gas, metastable $\mathrm{TiO}_{2}$ nanoparticles may have condensed by an epitaxial nucleation mechanism and grown on the surface of spinel. These $\mathrm{TiO}_{2}$ nanoparticles are disordered intergrowths of the two $\mathrm{TiO}_{2}$ polymorphs, anatase and rutile. These nanoparticles are inferred to have nucleated as anatase that underwent partial transformation into rutile. The local presence of the $\mathrm{TiO}_{2}$ nanoparticles and intergrowth of anatase and rutile imply that the disequilibrium back-reaction of spinel with the gas occurred on a short timescale, i.e., minutes to hours at maximum.

\section{INTRODUCTION}

Amoeboid olivine aggregates (AOAs) are the most common type of refractory inclusion in $\mathrm{CV}, \mathrm{CH}, \mathrm{CM}, \mathrm{CO}$, and $\mathrm{CR}$ carbonaceous chondrites, but show a significant variation in size between chondrites (Krot et al., 2004a). They are typically irregularly-shaped and fine-grained, and contain mostly forsteritic olivine, often associated with Fe,Ni-metal grains and lesser, variable amounts of refractory phases such as Al-Ti-bearing diopside, tanorthite, \pm spinel, \pm melilite, and \pm perovskite that commonly occur in Ca-Al-rich inclusions (CAIs) in carbonaceous chondrites. Based on their refractory mineralogy and oxygen isotopic compositions, AOAs are generally interpreted to represent the primary products of gas-solid condensation from the cooling solar nebula, which subsequently experienced high-temperature annealing and, in some cases, a small degree of melting (Grossman and Steele, 1976; Hashimoto and Grossman, 1987; Komatsu et al., 2001; Chizmadia et al., 2002; Weisberg et al., 2004; Fagan et al., 2004; Krot et al., 2004a, b, c; Krot et al., 2005; Ruzicka et al., 2012).

Refractory phases in individual AOAs show a range of textural occurrences. They are typically fine-grained and irregularly-shaped grains which occur interstitially to the dominant forsteritic olivine grains. Some of these phases are intergrown and form rounded and compact CAI-like objects. However, the formation mechanisms of refractory phases in AOAs are not fully understood and several possible origins have been proposed. These include: i) formation by direct nebular condensation followed by aggregation and subsequent annealing together with 
olivine (Grossman and Steele, 1976; Ruzicka et al., 2012); ii) formation by reactions between the nebular gas and condensed solids (Grossman and Steele, 1976; Grossman et al., 1979; Hashimoto and Grossman, 1987; Weisberg et al., 2004; Krot et al., 2004a,b,c; Krot et al., 2005; Zhang and Hsu, 2009; Ruzicka et al., 2012); or iii) formation by melting of anorthite and forsteritic olivine mixtures during thermal events in the hot solar nebula (Komatsu et al., 2009). Currently, there is no clear consensus as to the exact origin of these refractory phases in AOAs and all three different formational models remain viable.

In comparison with AOAs in other carbonaceous chondrite groups, the nature and origin of AOAs in the $\mathrm{CO} 3$ chondrite group have received relatively little attention. This situation has arisen, at least in part, because of the small size of AOAs in $\mathrm{CO} 3$ chondrites compared with other carbonaceous chondrites, as well as the extremely fine grain size of their constituent minerals. Nevertheless, the petrographic and compositional characteristics of AOAs in a suite of CO3 chondrites spanning a range of petrologic subtypes have been described previously by Rubin (1998) and Chizmadia et al. (2002). These scanning electron microscopy (SEM) and electron microprobe studies have characterized the detailed responses of AOAs to thermal metamorphism and have shown that AOAs are sensitive indicators of aqueous alteration coupled with thermal metamorphism in $\mathrm{CO} 3$ chondrites.

To date, constraints on the formation conditions and processes of AOAs in carbonaceous chondrites have come from mineralogical and isotopic studies using SEM, electron microprobe, and ion microprobe. No microstructural studies by transmission electron microscopy (TEM) have been performed on AOAs in any carbonaceous chondrites, even though such studies have the potential to provide additional insights into the thermal histories of these complex objects. In this study, we have used focused ion beam (FIB) sample preparation technique coupled with TEM to investigate the fine scale texture and mineralogy of refractory phases in one AOA (AOA 02) in the pristine CO3.0 chondrite, ALHA77307. ALHA77307 is particularly suited to this study because it is widely regarded as one of the least metamorphosed CO3 chondrites (Scott and Jones, 1990; Grossman and Brearley, 2005; Bonal et al., 2007; Kimura et al., 2008). Further, the detailed textural relationships and microstructures of the constituent phases in AOAs in CO3 chondrites can only be adequately characterized by TEM because of their extremely fine-grained characteristics. The goals of this study are to provide constraints on possible formational and thermal processes that affected refractory phases in AOAs and to understand the origins and thermal histories of AOAs. Preliminary results of this study were presented by Han and Brearley (2011a, b).

\section{ANALYTICAL METHODS}

A chip of the ALHA77307 CO3.0 chondrite from the Antarctic Meteorite Collection at NASA Johnson Space Center was kindly provided by the Antarctic Meteorite Working Group. Two demountable petrographic thin sections suitable for TEM studies were prepared from this sample. One of the thin sections used in this study has been previously coated with gold for ion microprobe studies. Although this coat had been removed, small flecks of gold are still present locally in cracks and fractures and are apparent in some images as high $\mathrm{Z}$ phases (Figs. 1 and 2). Both thin sections were initially characterized by SEM using backscattered electron (BSE) imaging and full spectral X-ray mapping. The BSE imaging and X-ray mapping were carried out at the University of New Mexico (UNM) using a FEI Quanta 3D Field Emission Gun SEM/FIB instrument fitted with an EDAX Apollo 40 SDD Energy Dispersive Spectroscopy (EDS) system 
with Genesis software. The instrument was operated at an accelerating voltage of $30 \mathrm{kV}$ in the high-vacuum mode, using beam currents of 2 to $23 \mathrm{nA}$ for BSE imaging and $23 \mathrm{nA}$ for X-ray mapping. Full thin section BSE mosaics and combined X-ray maps of $\mathrm{Mg} \mathrm{K \alpha}$ in red, $\mathrm{Ca} \mathrm{K} \alpha$ in green, and $\mathrm{Al} \mathrm{K} \alpha$ in blue were used to locate all AOAs in the two sections. Once located, individual AOAs including AOA 02 that contained significant modal abundances of Ca-Al-Tirich phases were studied in detail using BSE imaging and qualitative full spectral X-ray mapping on the same instrument to characterize their petrology and mineralogy.

Quantitative wavelength-dispersive spectroscopy (WDS) analyses of individual minerals were collected with a JEOL JXA-8200 electron microprobe at UNM. All analyses were obtained at an accelerating voltage of $15 \mathrm{kV}$, a beam current of $20 \mathrm{nA}$, and a spot size of $1 \mu \mathrm{m}$. Elemental calibration was carried out using CM Taylor Company Microprobe Standards as follows: $\mathrm{Mg}, \mathrm{Si}$, and $\mathrm{Fe}$ on olivine, $\mathrm{Al}$ and $\mathrm{K}$ on orthoclase, $\mathrm{Ca}$ on diopside, $\mathrm{Mn}$ on spessartine, $\mathrm{Cr}$ on chromite, $\mathrm{Na}$ on albite, $\mathrm{Ti}$ on rutile, and $\mathrm{V}$ on $\mathrm{V}$-metal. Data were reduced using the modified ZAF correction procedure.

For this study, one AOA (AOA 02) was selected for further detailed microstructural study using TEM. Four TEM sections were prepared from two refractory CAI-like objects from the AOA by the FIB technique, using the FEI Quanta 3D Field Emission Gun SEM/FIB instrument. Platinum (Pt) strips, $\sim 2 \mu \mathrm{m}$ wide and $\sim 2.5 \mu \mathrm{m}$ in thickness, were deposited across each area of interest to protect the TEM sections from ion beam damage during the sample preparation processes. The samples were extracted from the thin section by the in situ lift-out technique using an Omniprobe 200 micromanipulator and were attached to copper $(\mathrm{Cu}) \mathrm{TEM}$ half grids. Ion milling to electron transparency was carried out at an accelerating voltage of 30 $\mathrm{kV}$ and at a beam current gradually decreasing from $0.5 \mathrm{nA}$ to $50 \mathrm{pA}$ for the final stages of milling.

Detailed microstructural and microanalytical studies were conducted using a JEOL 2010 high resolution TEM (HRTEM) and a JEOL 2010F FASTEM field emission gun scanning TEM (STEM/TEM) instrument with a GATAN GIF 2000 energy filtered imaging system at UNM. Both instruments were operated at $200 \mathrm{kV}$. A variety of TEM techniques were used to characterize the samples in detail, including bright-field TEM (BF-TEM), high-resolution TEM (HR-TEM), dark-field scanning TEM (DF-STEM), and electron diffraction. Digital TEM images were acquired and processed using GATAN Digital Microscopy Suite $($ DMS) imaging software. In situ X-ray microanalyses were carried out using Oxford Instruments INCA 200 Energy Dispersive X-ray Spectroscopy System with Oxford Pentafet Ultrathin Window Detector (UTW). Data reduction was carried out using the Cliff-Lorimer thin film approximation using experimental and theoretical k-factors.

\section{RESULTS}

We found a total of 179 AOAs within a total of $\sim 80 \mathrm{~mm}^{2}$ of the two thin sections of ALHA77307. Our SEM observations of the AOAs in ALHA77307 are generally consistent with previous studies (Rubin, 1998; Chizmadia et al., 2002; Itoh et al, 2002).

\subsection{SEM Observations of AOA 02}

AOA 02 is an irregularly-shaped object, $370 \times 275 \mu \mathrm{m}$ in size that contains $\sim 30 \mathrm{vol} \%$ of refractory phases surrounded by relatively compact forsteritic olivine grains (Fig. 1). The refractory CAI-like objects (hereafter, S1, S2, S3, and S4) occur as four distinct, subrounded 
spinel-rich nodules which range in size from $50 \mu \mathrm{m}$ to $100 \mu \mathrm{m}$ (Figs. 1 and 2). Field emission gun SEM imaging and X-ray mapping show that each CAI-like object consists of a zoned sequence with a spinel-rich core, a thin layer consisting of a fine-grained intergrowth of spinel and Al-Ti-bearing diopside (henceforth, termed as an intergrowth layer), and a diopside rim. In addition, the $\mathrm{Ti} \mathrm{K} \alpha \mathrm{X}$-ray map reveals that $\mathrm{Ti}$ is preferentially concentrated in diopside grains and indicates that Al-Ti-rich diopside occurs both within the spinel-rich cores and in the innermost zone of the intergrowth layers (Fig. 1c). The spinel-rich cores are subrounded to rounded and range in size from $40 \mu \mathrm{m}$ to $55 \mu \mathrm{m}$. The spinel-rich core in S1 consists of an intergrowth of Al-Ti-rich diopside and spinel, but the spinel-rich cores in the other three objects contain very few Al-Ti-rich diopside grains. The spinel-rich core in S1 contains many pores, whereas in S2-S4 the spinel-rich cores have few pores. The layers between the spinel-rich cores and the diopside rims consist of intergrowths of fine-grained spinel and Al-Ti-rich diopside. The Al-Ti-rich diopside in these intergrowth layers is continuous with the diopside rim. The intergrowth layers of spinel and Al-Ti-rich diopside in all the objects contain pores. The intergrowth layers in S3 and S4 are continuous, but S1 and S2 have discontinuous layers due to the presence of metal grains in the case of S1 and melilite grains in the case of S2. The intergrowth layers in the four objects show different ranges of thicknesses as follows: 2-6 $\mu \mathrm{m}$ (S1), 3-20 $\mu \mathrm{m}$ (S2-S3), and 2-10 $\mu \mathrm{m}$ (S4). The diopside rims follow the intergrowth layers and completely surround all the spinel-rich objects. The diopside rims in each object also have different ranges of thicknesses: 1-10 $\mu \mathrm{m}$ (S1), 2-10 $\mu \mathrm{m}$ (S2), 1-15 $\mu \mathrm{m}$ (S3), and 1-6 $\mu \mathrm{m}$ (S4). Additionally, combined X-ray maps and qualitative EDS analyses confirm that two melilite grains are present along the edge of the spinel-rich core only in S2 (Figs. 1b and 1c). The melilite grains are elongated and have sizes of approximately $17 \times 4 \mu \mathrm{m}$ and $20 \times 8 \mu \mathrm{m}$. Both of these melilite grains are partially surrounded by $\sim 1-3 \mu \mathrm{m}$-sized pores followed by an intergrowth of Al-Ti-rich diopside and spinel (Fig. 2b). No perovskite occurs in any of the four CAI-like objects. Finally, forsteritic olivine completely encloses the four CAI-like objects. The grain boundaries between the surrounding olivine and the diopside rims of the CAI-like objects are sharp with no evidence of fine-scale intergrowths. The AOA also contains 3-25 $\mu \mathrm{m}$-sized Fe,Nimetal grains (Figs. 1a and 2).

\subsection{Mineral Compositions Obtained by Electron Microprobe}

Representative electron microprobe analyses of spinel, pyroxene, and olivine from AOA 02 are reported in Table 1. Olivine in AOA 02 is nearly pure forsterite $\left(\mathrm{Fa}_{0.3-0.9}\right)$ with $0.24-0.87$ wt $\% \mathrm{FeO}$ and typically has very low $\mathrm{Cr}_{2} \mathrm{O}_{3}, \mathrm{MnO}$, and $\mathrm{Na}_{2} \mathrm{O}$ contents $\leq 0.1 \mathrm{wt} \%$. Spinel in each of the CAI-like objects is very close to pure $\mathrm{MgAl}_{2} \mathrm{O}_{4}$ with $0.18-0.34 \mathrm{wt} \% \mathrm{FeO}$ and $<0.5 \mathrm{wt} \%$ $\mathrm{Cr}_{2} \mathrm{O}_{3}$. However, pyroxene shows large variations in $\mathrm{SiO}_{2}, \mathrm{TiO}_{2}, \mathrm{Al}_{2} \mathrm{O}_{3}$, and $\mathrm{MgO}$ contents, but relatively constant $\mathrm{CaO}$ contents ranging from $23.43 \mathrm{wt} \%$ to $25.29 \mathrm{wt} \%$. For example, the $\mathrm{Al}_{2} \mathrm{O}_{3}$ contents in pyroxene range from $3.56 \mathrm{wt} \%$ to $21.39 \mathrm{wt} \%$ and the $\mathrm{TiO}_{2}$ contents from $0.14 \mathrm{wt} \%$ to $7.36 \mathrm{wt} \%$.

\subsection{Microstructural Observations of Refractory CAI-Like Objects in AOA 02}

In order to understand the textural and compositional characteristics of the CAI-like objects and their relationship to the forsteritic olivine in AOA 02, four TEM sections were prepared from two refractory objects ( $\mathrm{S} 1$ and $\mathrm{S} 2$ ) from the AOA. The locations of these FIB sections (hereafter, FIB A, B, C, and D) are shown in Figures 2a and 2b; FIB A and B were extracted from S2 and FIB C and D from S1. FIB A was prepared across a region of S2 where 
two melilite grains occur and FIB B was cut across the zonal sequence from the spinel-rich core of $\mathrm{S} 2$ to the surrounding olivine of the AOA. FIB B was not cut normal to the diopside rim, but at an oblique angle. In S1, FIB C was cut from the spinel-rich core near the diopside rim and FIB $\mathrm{D}$ from a complex spinel-diopside intergrowth in the spinel-rich core.

All four FIB sections extracted from the two CAI-like objects have textures which are highly compact with no evidence of pores between refractory phases. These sections show complex intergrowths of refractory phases, in most cases spinel and Al-Ti-bearing diopside, with highly irregular shapes. Curved and embayed grain boundaries between refractory phases are frequently observed. No perovskite was found in any of the four FIB sections at the nanometer scale, consistent with the SEM observations. We do not find any crystallographic orientation relationships between any of refractory phases.

Only FIB A from S2 contains gehlenitic melilite grains that dominate the section, coexisting with spinel and Al-Ti-bearing diopside (Fig. 3). The other three FIB sections do not contain melilite even at the nanometer scale (Figs. 4-6). The melilite grains, 0.5-4 $\mu \mathrm{m}$ in size, are highly irregularly shaped and are typically embayed by spinel and Al-Ti-bearing diopside. In FIB A, spinel and Al-Ti-bearing diopside are also irregular in shape and range in size from $0.4 \mu \mathrm{m}$ to $3.5 \mu \mathrm{m}$.

FIB B cut from the diopside rim of S2 contains forsteritic olivine, spinel, Al-Ti-bearing diopside, and anorthite (Fig. 4). This section contains the zonal sequence from the spinel core through the complex intergrowth of fine-grained diopside, spinel, and anorthite to the surrounding olivine that is part of the enclosing AOA. The core region of this section contains spinel grains, which are in contact with diopside grains. One spinel grain in the core region contains randomly-distributed dislocations. The central part of the section is a $12 \mu \mathrm{m}$-wide intergrowth layer dominated by Al-Ti-bearing diopside with minor spinel and anorthite. Minor anorthite occurs exclusively within the intergrowth layer. Most of the grains within this intergrowth layer have highly curved, unequilibrated grain boundaries. Diopside grains in the intergrowth layer have a size range of $0.2-4.5 \mu \mathrm{m}$. In the intergrowth layer, spinel ranges in size from $0.2 \mu \mathrm{m}$ to $1.5 \mu \mathrm{m}$ and anorthite from $1 \mu \mathrm{m}$ to $2 \mu \mathrm{m}$. Spinel and anorthite grains are generally enclosed by diopside grains and are occasionally in contact with each other. Alternatively, some spinel grains completely envelop subrounded diopside grains which range in size from $0.3 \mu \mathrm{m}$ to $0.5 \mu \mathrm{m}$. No olivine grains are found in the intergrowth layer, except for minor olivine (0.8-4.5 $\mu \mathrm{m}$ in size) in contact with $0.6-1.5 \mu \mathrm{m}$-sized diopside grains in the outer region of the intergrowth layer. At the boundary between the intergrowth layer and the forsteritic olivine of the AOA, finer-grained olivine and diopside grains have almost straight grain boundaries with equilibrium $120^{\circ}$ triple junctions.

Both FIB C and D prepared from the spinel-rich core of S1 consist of dense aggregates of submicron to micron-sized spinel and Al-Ti-rich diopside (Figs. 5 and 6). The BSE images of the CAI-like objects suggest that the cores of each of the objects appear to be large single spinel crystals (40-55 $\mu \mathrm{m}$ in size) with no evidence of internal grain boundaries (Fig. 2), but our TEM observations reveal that the core consists of a compact, polycrystalline aggregate of spinel grains (0.4-12 $\mu \mathrm{m}$ in size) with minor diopside. The grain boundaries between spinel grains in the spinel-rich core are almost straight and show equilibrated grain boundary microstructures with well-developed $120^{\circ}$ triple junctions (Fig. 5). Sometimes, the grain boundaries between spinel and diopside grains are highly curved disequilibrium grain boundaries (Fig. 6). The grain sizes of spinel are 0.7-5.5 $\mu \mathrm{m}$ for FIB C and 0.4-12 $\mu \mathrm{m}$ for FIB D. Diopside ranges in size from $0.5 \mu \mathrm{m}$ to $3.5 \mu \mathrm{m}$ for FIB C and from $0.3 \mu \mathrm{m}$ to $3 \mu \mathrm{m}$ for FIB D. 
One feature unique to FIB $\mathrm{D}$ is the presence of numerous $\mathrm{TiO}_{2}$ nanoparticles along the grain boundaries between spinel grains and between diopside and spinel grains, which will be described in detail below.

\subsection{Mineral Compositions Obtained by TEM}

Spinel from all FIB sections is nearly end-member $\mathrm{MgAl}_{2} \mathrm{O}_{4}$ and contains low concentrations of $\mathrm{FeO}<0.9 \mathrm{wt} \%$ and $\mathrm{SiO}_{2}<1.7 \mathrm{wt} \%$. Melilite occurs only in FIB A and is gehlenitic with an average composition of $\AA^{\circ} k_{30}$ and an overall range of $\AA \mathrm{Ak}_{20-46}$. In FIB B, olivine is very close to pure forsterite $\left(\mathrm{Fa}_{0.2-0.3}\right)$ and plagioclase is nearly pure anorthite, $\mathrm{CaAl}_{2} \mathrm{Si}_{2} \mathrm{O}_{8}$. Both olivine and plagioclase have very uniform compositions in FIB B.

Pyroxene from the four FIB sections is highly variable in composition with $\mathrm{Al}_{2} \mathrm{O}_{3}$ and $\mathrm{TiO}_{2}$ contents (Fig. 7). This compositional variation occurs over very short distances between diopside grains and within single diopside grains. Collectively, pyroxene compositions from all four FIB sections show a range of $\mathrm{Al}_{2} \mathrm{O}_{3}$ contents from $0 \mathrm{wt} \%$ to $28 \mathrm{wt} \%$ and $\mathrm{TiO}_{2}$ contents from $0 \mathrm{wt} \%$ to $14 \mathrm{wt} \%$. In general, pyroxene grains in the spinel-rich cores of the CAI-like objects are more Al-Ti-rich compared to those in the diopside rims of the objects. Figure 7 shows that there are two distinct compositional groups of pyroxene based on their $\mathrm{Al}_{2} \mathrm{O}_{3}$ and $\mathrm{TiO}_{2}$ contents. The first group has only been found in FIB $\mathrm{B}$ and has a range of $\mathrm{Al}_{2} \mathrm{O}_{3}$ contents from 0 wt $\%$ to 10 wt $\%$ with uniform, very low $\mathrm{TiO}_{2}$ contents $\leq 1 \mathrm{wt} \%$. The second group occurs in all the FIB sections and has $\mathrm{Al}_{2} \mathrm{O}_{3}$ contents higher than $10 \mathrm{wt} \%$, which are positively correlated with $\mathrm{TiO}_{2}$ contents ranging from $0 \mathrm{wt} \%$ to $14 \mathrm{wt} \%$. Texturally, the first pyroxene group with $0-10 \mathrm{wt} \%$ $\mathrm{Al}_{2} \mathrm{O}_{3}$ and $\leq 1 \mathrm{wt} \% \mathrm{TiO}_{2}$ only occurs at the outer layer of the diopside rim in FIB B (Fig. 4). The detailed pyroxene chemistry for each FIB section is discussed below.

FIB A cutting across two melilite grains in S2 (Fig. 2b) shows random distributions of pyroxene compositions with an overall range of 10-25 wt $\% \mathrm{Al}_{2} \mathrm{O}_{3}$ and 0.6-14 wt $\% \mathrm{TiO}_{2}$ contents (Fig. 7).

Only FIB B was cut across a complete sequence of the spinel-rich core of S2 to the surrounding olivine of the AOA (Fig. 2b). Fine-grained pyroxene grains $\leq \sim 4.5 \mu \mathrm{m}$ in size from FIB B show wide variations in their compositions along the sequence of the section, with an overall range of $0.5-27 \mathrm{wt} \% \mathrm{Al}_{2} \mathrm{O}_{3}$ and $0-11 \mathrm{wt} \% \mathrm{TiO}_{2}$ contents over a distance of $\sim 12 \mu \mathrm{m}$ (Fig. 7). The changes in $\mathrm{Al}_{2} \mathrm{O}_{3}$ contents of pyroxene occur progressively with increasing distance from the interface with olivine $\left(0.5 \mathrm{wt} \% \mathrm{Al}_{2} \mathrm{O}_{3}\right)$ to the interface with the spinel-rich core $(27 \mathrm{wt} \%$ $\mathrm{Al}_{2} \mathrm{O}_{3}$ ) (Fig. 8). However, pyroxene has a relatively constant range of $\mathrm{TiO}_{2}$ contents $(\leq 1 \mathrm{wt} \%)$ through the middle of FIB B, but has $\mathrm{TiO}_{2}$ contents that dramatically increase by $\sim 11 \mathrm{wt} \%$ over a very short distance $(\leq \sim 2 \mu \mathrm{m})$ towards the contact with the spinel-rich core while the $\mathrm{Al}_{2} \mathrm{O}_{3}$ contents also increase (Fig. 8). These increases in $\mathrm{Al}_{2} \mathrm{O}_{3}$ and $\mathrm{TiO}_{2}$ contents are apparent within single pyroxene grains immediately adjacent to spinel grains in the core. Thus, in terms of pyroxene composition, FIB B consists of the zonal sequence of Al-Ti-poor, Al-rich Ti-poor, and Al-Ti-rich diopside towards the spinel-rich core.

FIB $\mathrm{C}$ and $\mathrm{D}$ were prepared from the spinel-rich core of $\mathrm{S} 1$ toward the surrounding diopside rim (Fig. 2a). Pyroxene in these two sections shows different ranges of $\mathrm{Al}_{2} \mathrm{O}_{3}$ and $\mathrm{TiO}_{2}$ contents (Fig. 7): 13-28 wt $\% \mathrm{Al}_{2} \mathrm{O}_{3}$ and 2.6-14 wt $\% \mathrm{TiO}_{2}$ for $\mathrm{FIB} \mathrm{C}$ and 17-25 wt $\% \mathrm{Al}_{2} \mathrm{O}_{3}$ and 8.4-14 $\mathrm{wt} \% \mathrm{TiO}_{2}$ for FIB D. In FIB C, pyroxene close to the center of the spinel-rich core is enriched in $\mathrm{TiO}_{2}$ contents by $\sim 10 \mathrm{wt} \%$ compared to pyroxene near the diopside rim, despite randomly-distributed $\mathrm{Al}_{2} \mathrm{O}_{3}$ contents though the section. However, there are no clear relationships between pyroxene compositions and their location in FIB D. 


\section{5. $\mathrm{TiO}_{2}$ Nanoparticles}

Within FIB D, numerous nanoparticles, $20-180 \mathrm{~nm}$ in size, decorate the grain boundaries between spinel and Al-Ti-rich diopside grains and between neighboring spinel grains (Fig. 9). No nanoparticles have been observed within the interiors of the spinel and diopside grains. The nanoparticles are typically elongated, and faceted to subrounded. Energy dispersive X-ray spectra obtained from several nanoparticles by TEM show that the major elements present are Ti and $\mathrm{O}$ with smaller peaks for $\mathrm{Al}, \mathrm{Mg}, \mathrm{Si}$, and $\mathrm{Ca}$ (Fig. 10a). The intensity of the $\mathrm{Al}, \mathrm{Mg}, \mathrm{Si}$, and Ca peaks was dependent on the extent of the peak overlap with adjacent spinel and diopside, and in most cases $\mathrm{Al}$ and $\mathrm{Mg}$ were most intense due to the presence of spinel grains. We therefore attribute these peaks to extraneous X-ray contributions from the surrounding phases and conclude that these nanoparticles are pure Ti oxides. In addition, energy-filtered TEM (EF-TEM) images are consistent with the presence of pure Ti oxide (Figs. 10b and 10c).

Bright-field TEM images show that the $\mathrm{TiO}_{2}$ nanoparticles exhibit a complex striated texture (Fig. 11a). High resolution TEM images of the nanoparticles show lattice fringes with unit-cell scale disorder and twinning (Fig. 11b). In addition, Fast Fourier Transform (FFT) analyses of HR-TEM images of the nanoparticles show streaking of diffraction maxima indicative of a disordered intergrowth of phases (Figs. 11c and 11d). Figures 11c and 11d are FFT patterns of HR-TEM images of one nanoparticle showing a detail of the complex microstructures of the nanoparticle. The most intense diffraction maxima can be matched and indexed as the [111] zone axis of rutile and the weaker maxima are consistent with the [131] zone axis of anatase; the [111] zone axis of rutile is parallel to the [131] zone axis of anatase and the $(1 \overline{1} 0)$ plane in rutile is parallel to the $(10 \overline{1})$ plane in anatase. Analysis of the FFT patterns of the nanoparticles shows that the observed nano-scale twinning appears to occur exclusively within rutile on the (101) plane, the expected twin plane for this polymorph of $\mathrm{TiO}_{2}$ (Deer et al., 1992).

Electron diffraction analyses show that all the $\mathrm{TiO}_{2}$ nanoparticles along individual grain boundaries are in the same crystallographic orientation. In addition, HR-TEM images show that the lattice fringes of the $\mathrm{TiO}_{2}$ nanoparticles are parallel to those of the neighboring spinel grains (Fig. 12a) showing that they are crystallographically oriented relative to the spinel grains. In Figures $12 b$ and 12c, FFT analyses of HR-TEM images of single nanoparticles show that the [010] zone axes of rutile nanoparticles are parallel to the [111] zone axis of spinel with (100) rutile $/ /(\overline{101})_{\text {spinel }}$. These crystallographic relationships are shown only between $\mathrm{TiO}_{2}$ nanoparticles and spinel; no similar relationships have been observed between the nanoparticles and diopside. Spinel and diopside whose mutual grain boundaries are decorated by the nanoparticles do not share any specific crystallographic orientation relationship.

\section{DISCUSSION}

\subsection{Refractory Ca-Al-Rich Phases in AOA 02}

The refractory CAI-like objects in AOA 02 from ALHA77307 we studied are mineralogically zoned, fine-grained CAIs which have a spinel-rich core surrounded by a rim of diopside (Figs. 1 and 2). These objects are texturally very similar to those that have been described previously in AOAs found in $\mathrm{CV}, \mathrm{CR}$, and $\mathrm{CM}$ chondrites and the unique carbonaceous chondrite Acfer 094 (Krot et al., 2004a) as well as spinel-pyroxene inclusions, a common type of CAI found in CO3 (Russell et al., 1998; Han, 2014) and CM chondrites 
(MacPherson and Davis, 1994; Rubin, 2007). However, there are important mineralogical differences from AOA 02. First, melilite is a very rare phase in the CAI-like objects in AOA 02 (Figs. 1 and 2) as well as other AOAs in ALHA77307; among 179 AOAs, only two AOAs including AOA 02 contain a few melilite grains that occur in zoned CAI-like objects (Han and Brearley, 2015). These observations are consistent with Chizmadia et al. (1998) and Itoh et al. (2002) who did not report any melilite in AOAs from the ALHA77307 and Yamato 81020 CO3.0 chondrites. In contrast, melilite typically occurs in the core of CAI-like objects in AOAs in CV, CR, and Acfer 094 chondrites (Krot et al., 2004a). Secondly, the CAI-like objects in AOA 02 contain few anorthite grains surrounded by Al-Ti-bearing diopside and spinel in the intergrowth layer in FIB B (Fig. 4). These anorthite grains were detectable only at the TEM scale. The rare occurrence of anorthite in AOA 02 is contrary to its common occurrence as finegrained intergrowths mostly with diopside in many AOAs in ALHA77307 (Chizmadia et al., 1998; Itoh et al., 2002; Han and Brearley, 2015) and other carbonaceous chondrites even at the SEM scale (Krot et al., 2004a). Possible scenarios for the dearth of melilite and anorthite in AOA 02 will be discussed further below.

We observe a large variation in pyroxene composition with a zonation from Al-Ti-poor to Al-Ti-rich diopside toward the spinel core of the CAI-like object (S2) in AOA 02 (Figs. 7 and 8). The similar compositional trend has been reported on a larger scale from AOAs in the Allende CV3 chondrite (Hashimoto and Grossman, 1987) and in the Vigarano CV3 chondrite (Bullock and MacPherson, 2009). Pyroxene layers in Wark-Lovering (WL) rims are consistently zoned with Al and often Ti decreasing away from the CAIs (e.g., Wark and Lovering, 1977; MacPherson et al., 1981; Ruzicka, 1997; Wark and Boynton, 2001; Simon et al., 2007), which is also comparable to the observed pyroxene zonation in AOA 02 (Fig. 8). In addition, pyroxene layers in WL rims share the microstructures with the diopside rim on the CAI-like objects in AOA 02 (Zega et al., 2007; 2009; 2010; Keller et al., 2013; Han et al., 2015), as follows: i) both layers consist of polycrystalline aggregates of nanometer-to-micrometer-sized grains; ii) all pyroxene grains are randomly-oriented with respect to one another; iii) all pyroxene grains share irregular grain boundaries with each other; and iv) most pyroxene grains are defect-free. These compositional and textural similarities between two occurrences of pyroxene suggest that both pyroxene may have formed by similar processes and conditions (i.e., gas-solid condensation under disequilibrium conditions), which will be discussed in detail below.

\subsection{Condensation Origin and Possible Gas-Solid Reactions}

Previous petrologic and mineralogical studies have suggested that AOAs consisting of olivine and refractory phases formed by condensation and reactions of condensate solids with a nebular gas in a hot solar nebula on cooling (Grossman and Steele, 1976; Hashimoto and Grossman, 1987; Komatsu et al., 2001; Weisberg et al., 2004; Fagan et al., 2004; Krot et al., 2004a,b,c; Krot et al., 2005). The condensation origin is generally supported by the similarity of the observed mineralogical sequence found in AOAs to the thermodynamically-predicted equilibrium condensation sequence during cooling of a hot solar nebula (Ebel, 2006). Our new observations indicate that the spinel-rich cores of the refractory CAI-like objects in AOA 02 certainly record gas-solid condensation under equilibrium conditions. In contrast, the intergrowth layers of these objects exhibit significant evidence of a high degree of textural and compositional disequilibrium implying complex thermal histories.

Our new SEM and TEM observations show that the spinel-rich cores of the refractory CAI-like objects consist of dense aggregates of spinel grains with equilibrium grain boundary 
structures (Fig. 5) indicative of formation by equilibrium condensation and subsequent annealing at high temperatures. These textures contrast with the highly disequilibrium textures of the complex zone of intergrown phases which surround the spinel and melilite grains (Fig. 4). Both spinel and melilite have textural characteristics which indicate that they have been partially replaced by diopside with highly variable compositions. We conclude, based on these observations, that both spinel and melilite represent the earliest-formed primary phases in these refractory CAI-like objects that subsequently underwent reactions to form diopside under conditions far from equilibrium. Combined with previous studies, it seems likely that the primary core assemblages of spinel and melilite represent nebular condensates that formed by equilibrium condensation processes.

We now consider in more detail the possible reaction processes and conditions, under which these two phases reacted to form the surrounding intergrowth layer of Al-Ti-bearing diopside and associated phases and the diopside rim. Although melilite and spinel are closely spatially associated, the assemblage of reaction product phases associated with these two phases is slightly different. We therefore consider them separately in the following discussion for simplicity. However, both phases were likely to be undergoing reactions at the same time and there were certainly interactions between the two phases as the reactions proceeded. Our observations indicate that there are localized differences in the mineral assemblages which we interpret as the result of highly localized mineralogical controls on the reaction pathways. Further, none of the equilibrium reactions proposed in previous studies exactly matches the mineralogical and textural observations.

\subsubsection{Melilite Gas-Solid Reactions}

Our TEM observations from FIB A indicate that melilite reacted with the nebular gas and has been partially replaced by complex intergrowths of fine-grained Al-Ti-rich diopside, with no evidence for the formation of anorthite. The reactions involving melilite clearly did not go to completion and so melilite coexists with spinel and Al-Ti-rich diopside.

Based on equilibrium condensation models, several reactions for the interaction of melilite with a solar nebular gas have been proposed to explain the observed phase assemblages and chemical compositions of refractory phases in AOAs. Although neither textural nor chemical equilibrium appear to have been reached in the CAI-like objects in AOA 02, these calculations provide a useful framework for interpreting our observations. Krot et al. (2004a) presented two possible gas-solid reactions that consume melilite:

$$
\begin{aligned}
& \text { (1) } \mathrm{Ca}_{2} \mathrm{Al}_{2} \mathrm{SiO}_{7(\mathrm{~s})}+3 \mathrm{SiO}_{(\mathrm{g})}+3 \mathrm{Mg}_{(\mathrm{g})}+6 \mathrm{H}_{2} \mathrm{O}_{(\mathrm{g})}=2 \mathrm{CaMgSi}_{2} \mathrm{O}_{6(\mathrm{~s})}+\mathrm{MgAl}_{2} \mathrm{O}_{4(\mathrm{~s})}+6 \mathrm{H}_{2(\mathrm{~g})} \\
& \text { melilite diopside spinel } \\
& \text { (2) } \mathrm{Ca}_{2} \mathrm{Al}_{2} \mathrm{SiO}_{7(\mathrm{~s})}+3 \mathrm{SiO}_{(\mathrm{g})}+\mathrm{Mg}_{(\mathrm{g})}+4 \mathrm{H}_{2} \mathrm{O}_{(\mathrm{g})}=\mathrm{CaAl}_{2} \mathrm{Si}_{2} \mathrm{O}_{8(\mathrm{~s})}+\mathrm{CaMgSi}_{2} \mathrm{O}_{6(\mathrm{~s})}+4 \mathrm{H}_{2(\mathrm{~g})}
\end{aligned}
$$

Reaction (1) appears to be a viable reaction to explain the complex intergrowth of fine-grained melilite, spinel, and diopside that occurs in FIB A (Fig. 3). However, in reaction (1), spinel is a reaction product, which is inconsistent with the textural observations, for example, embayments into spinel in the cores (Fig. 2) and a corroded appearance of spinel in the intergrowth layer (Fig. 4), which suggest that the edge of the compact spinel core of the objects is being replaced, rather than forming during the reaction. In addition, the reaction cannot explain the formation of 
diopside with the observed wide range of $\mathrm{Al}$ contents (Fig. 7). Reaction (2) is unlikely due to a complete lack of anorthite associated with either diopside or melilite in FIB A. However, reaction (2) seems more probable for the formation of fine-grained intergrowth of anorthite and diopside found in FIB B (Fig. 4) if melilite was extensively reacted, as discussed in detail below.

\subsubsection{Spinel Gas-Solid Reactions}

Our SEM and TEM observations show that spinel is the main phase in the cores of each of the CAI-like objects in AOA 02 (Figs. 1 and 2) and that the spinel-rich cores have a complex, embayed intergrowth texture around their peripheries (Fig. 4). The intergrowth zone is best seen in FIB B and consists of fine-grained spinel, diopside, and rare anorthite (Fig. 4), which we interpret as representing a reaction zone in which spinel is being consumed. Two reactions involving spinel as a reactant have been proposed by Krot et al. (2004a):

$$
\begin{aligned}
& \text { (3) } 3 \mathrm{Ca}_{2} \mathrm{Al}_{2} \mathrm{SiO}_{7(\mathrm{~s})}+\mathrm{MgAl}_{2} \mathrm{O}_{4(\mathrm{~s})}+5 \mathrm{SiO}_{(\mathrm{g})}+\mathrm{Mg}_{(\mathrm{g})}+6 \mathrm{H}_{2} \mathrm{O}_{(\mathrm{g})} \\
& \text { melilite spinel } \\
& =\left[4 \mathrm{CaAl}_{2} \mathrm{SiO}_{6}+2 \mathrm{CaMgSi}_{2} \mathrm{O}_{6}\right]_{(\mathrm{px} \mathrm{ss})}+6 \mathrm{H}_{2(\mathrm{~g})} \\
& \text { pyroxene solid solution }
\end{aligned}
$$

(4) $2 \mathrm{MgAl}_{2} \mathrm{O}_{4(\mathrm{~s})}+2 \mathrm{CaMgSi}_{2} \mathrm{O}_{6(\mathrm{~s})}+\mathrm{SiO}_{(\mathrm{g})}+\mathrm{H}_{2} \mathrm{O}_{(\mathrm{g})}$

$$
\text { spinel diopside }
$$

$$
\begin{aligned}
& =\mathrm{CaAl}_{2} \mathrm{Si}_{2} \mathrm{O}_{8(\mathrm{~s})}+2 \mathrm{Mg}_{2} \mathrm{SiO}_{4(\mathrm{~s})}+\mathrm{CaAl}_{2} \mathrm{SiO}_{6(\mathrm{~s})}+\mathrm{H}_{2(\mathrm{~g})} \\
& \text { anorthite forsterite Al-diopside }
\end{aligned}
$$

We have observed high $\mathrm{Al}_{2} \mathrm{O}_{3}$ contents in diopside that is in contact with just spinel in $\mathrm{FIB} \mathrm{C}$ and $\mathrm{D}$ and with both melilite and spinel in FIB $\mathrm{A}$ (Fig. 7). In FIB $\mathrm{B}$, the $\mathrm{Al}_{2} \mathrm{O}_{3}$ contents in diopside increase progressively as the interface with spinel is approached (Fig. 8). These compositional variations can be explained by reaction (3); Krot et al. (2004a) noted that in the earliest stages of reaction (3), the diopside is Al-poor, but becomes Al-rich as the reaction proceeds, because twice as much Ca-Tschermak's (CATS) pyroxene or kushiroite (Kimura et al., 2009) as diopside is produced. For the melilite-bearing FIB A, reaction (3) appears to have occurred, but did not go to completion leaving relict reactant melilite in the mineral assemblage. The rarity of melilite in the CAI-like objects indicates that it has been extensively replaced by reaction (3); no melilite relicts have been found in any of the other three FIB sections. However, our data also suggest that the abundance of primary melilite in the spinel-rich cores of these CAI-like objects was also low and therefore reaction (3) played only a minor role in the mineralogical evolution of the objects we studied. Rather, a reaction involving only spinel as the main solid phase to react with the nebular gas appears more favorable for the CAI-like objects in AOA 02. Spinel in the cores may have undergone very minimal reaction and have been consumed only during the very earliest stages of reactions with the gas phase.

Anorthite only occurs in the middle of the intergrowth layer rimming the spinel-rich cores in FIB B and is completely surrounded by intergrowths of Al-Ti-bearing diopside and minor spinel (Fig. 4). The small amount of anorthite in the intergrowth layer may have formed by either reaction (2) or (4). Similarly, Weisberg et al. (2004) suggested the formation of anorthite through the reaction of early-condensed melilite with $\mathrm{SiO}$ in the gas phase (reaction (2)) or the reaction of spinel and diopside with the gas phase (reaction (4)), based on textural observations of anorthite which occurs at locations formerly occupied by melilite. Based on 
reaction (4), two moles of forsterite form for every one mole of anorthite produced, indicating that a significant amount of forsterite should have been produced and be associated with anorthite if reaction (4) occurred. However, forsteritic olivine is not found in the intergrowth layer and only occurs in contact with diopside at the outer region of the intergrowth layer (Fig. 4), which suggests that reaction (4) is less viable. An alternative is that anorthite formed by reaction (2) where a small amount of melilite was present in the precursor layer. However, reaction (2) becomes possible only after the pyroxene reaches 20 mol\% CATS (Krot et al., 2004a). In AOA 02, Al-rich diopside in the intergrowth layer significantly exceeds $20 \mathrm{~mol} \%$ CATS (Fig. 4), suggesting that reaction (2) may have been kinetically inhibited. Due to kinetic effects, diopside could have formed preferentially instead of anorthite.

Thermodynamic equilibrium calculations at temperatures of 1,000-1,600 K and pressures of $10^{-3}-10^{-8}$ bar presented by Krot et al. (2004a) show that the phase boundaries of reactions (1)(4) are parallel to each other in a plot of pressure vs. temperature and that a reaction sequence of reaction (3) followed by (2), (1), and (4) exists during cooling of the solar nebula, although absolute temperatures of each of the reactions vary. This reaction sequence implies that the refractory CAI-like objects in AOA 02 may have formed by a sequence of reactions with the nebular gas. It is also possible that essentially all these reactions could have proceeded simultaneously around the cores consuming both spinel and melilite, but under conditions that departed significantly from equilibrium. Overall, the reactions have resulted in the development of complex intergrowth layers around the periphery of the spinel-rich cores observed in AOA 02. As this layer increased in thickness, the spinel-rich cores became isolated from the nebular gas and no longer participated as reactant phase. Once isolation of the spinel-rich cores of the objects had occurred, diopside with rapidly decreasing Al contents condensed from the cooling solar nebula, ultimately forming the diopside rim as the outermost layer of the CAI-like objects.

Finally, forsterite must have been formed by direct condensation from the nebular gas, due to no textural and chemical evidence of reaction relationship with other phases. The condensation origin of AOA forsterite is entirely consistent with previous works (Krot et al., 2004a). After or during reactions of Ca-Al-rich phases with the nebular gas, forsterite would have been aggregated with the CAI-like objects to form AOAs.

A problem with the direct application of the reactions (1)-(4) discussed above to the mineral assemblages found in the intergrowth layers in AOA 02 is that they cannot readily explain the formation of Al-rich diopside with elevated Ti contents that commonly occurs in all the FIB sections (Fig. 7). We observed highly elevated Al and Ti contents in diopside near spinel grains in all the FIB sections and near melilite grains in FIB A. Equilibrium condensation calculations predict that all $\mathrm{Ti}$ in the gas phase will condense as perovskite before the onset of diopside condensation (Ebel, 2006). Consequently, diopside that forms during equilibrium condensation has relatively low $\mathrm{Ti}$ concentrations. Therefore a mechanism to explain the incorporation of $\mathrm{Ti}$ into diopside is crucial to understanding how the refractory CAI-like objects formed.

One possible scenario is that high $\mathrm{Ti}$ contents in diopside were derived from an earlycondensed Ti-rich phase (e.g., perovskite) associated with primary melilite and spinel in the cores of these CAI-like objects in AOA 02. Based on mineralogical and petrological observations of AOAs in CR chondrites, Weisberg et al. (2004) proposed the reaction of melilite and perovskite with the gas phase to form spinel and Al-Ti-rich diopside. This reaction could potentially explain our observations, but requires that perovskite was completely consumed during the reaction with melilite. Although this reaction is certainly viable, the complete absence 
of perovskite in any of the CAI-like objects in AOA 02, even down to the nano-scale, from both SEM and TEM observations is problematic. Further, our survey of AOAs in ALHA77307 shows that perovskite is an extremely rare phase within refractory CAI-like objects; of 179 AOAs we have observed, only two contain perovskite grains (Han and Brearley, 2015). If perovskite was a common phase in refractory CAI-like objects, we would expect to see some evidence of its presence in more AOAs. Moreover, if perovskite was present as a primary phase in these objects, our observations require that it would have had to be present at very specific locations, i.e., in a very narrow zone exactly at the interface with spinel and melilite grains, in order to form Al-Tirich diopside at these interfaces. This textural relationship is unlikely because equilibrium condensation calculations show that perovskite is predicted to condense before spinel and melilite (Ebel, 2006). In addition, El Goresy et al. (2002) and Lin et al. (2003) reported that AlTi-rich diopside occurs as rims on perovskite in compact Type A CAIs from the Efremovka $\mathrm{CV}_{\text {red }}$ chondrite and from the Ningqiang carbonaceous chondrite. Based on the textural relationship between diopside and perovskite and a high enrichment of $\mathrm{Ti}$ in diopside, El Goresy et al. (2002) and Lin et al. (2003) suggested that Al-Ti-rich diopside formed by reaction of perovskite with a CAI melt during crystallization. However, there are neither such relationship nor textures in AOA 02 which would suggest that melting was an important process in the formation of the observed reaction textures. Based on these observations, we infer that it is unlikely that perovskite was present as a primary phase in AOA 02 and therefore the reaction of perovskite with melilite and spinel is not responsible for the formation of Ti-rich, Al-diopside that we have observed in AOA 02 and other AOAs in ALHA77307.

If perovskite was never present as a primary condensed phase in AOA 02, then an external source of $\mathrm{Ti}$ is required to explain the formation of Ti-rich, Al-diopside. The only possible external source appears to be a partially condensed nebular gas that underwent reaction with both primary melilite and spinel. In this process, melilite and spinel reacted with the Tisaturated nebular gas, forming Al-Ti-rich diopside as the first pyroxene composition in the reaction:

$$
\begin{aligned}
& \text { (5) } 3 \mathrm{Ca}_{2} \mathrm{Al}_{2} \mathrm{SiO}_{7(\mathrm{~s})}+\mathrm{MgAl}_{2} \mathrm{O}_{4(\mathrm{~s})}+2 \mathrm{Ti}_{(\mathrm{g})}+4 \mathrm{SiO}_{(\mathrm{g})}+7 \mathrm{H}_{2} \mathrm{O}_{(\mathrm{g})} \\
& \text { melilite spinel } \\
& =\left[2 \mathrm{CaTiAlSiO}_{6}+3 \mathrm{CaAl}_{2} \mathrm{SiO}_{6}+\mathrm{CaMgSi}_{2} \mathrm{O}_{6}\right]_{(\mathrm{px} \mathrm{ss})}+7 \mathrm{H}_{2(\mathrm{~g})} \\
& \text { pyroxene solid solution }
\end{aligned}
$$

As the reaction (5) proceeded and the gas became depleted in $\mathrm{Ti}$, the condensing pyroxene composition evolved outward from Al-Ti-rich diopside at the interface with primary spinel and melilite to Al-Ti-poor diopside that occurs on the outer part of the intergrowth layer. In this reaction, primary melilite may have served as a source of $\mathrm{Ca}$ to form diopside during the earliest stages of the reaction. However, condensation of $\mathrm{Ca}$ from the nebular gas must also have been important for the formation of diopside, once melilite in the cores of the CAI-like objects has either reacted or been isolated from a gas by the intergrowth layer of spinel and Al-Ti-rich diopside.

The compositional profiles for Ti through the diopside rims are much steeper than the Al profiles. This evidence might suggest that diffusional processes were involved in the formation of the zoning profiles as a result of slower diffusion of Ti compared with Al. However, it seems improbable for several reasons that diffusion played a significant role in the development of the compositional zoning. First, the diffusivities of $\mathrm{Al}$ and $\mathrm{Ti}$ in diopside are comparable (Cherniak 
and Liang, 2012; Sautter et al., 1988) and therefore differences in diffusion rates cannot be advocated to explain the difference in their profiles. Secondly, there is no apparent source of $\mathrm{Ti}$ associated with spinel to diffuse into the diopside. Finally, the preservation of $\mathrm{TiO}_{2}$ nanoparticles consisting of intergrowths of rutile and anatase indicates that formation of the diopside rims occurred extremely rapidly to prevent coarsening of the nanoparticles and complete transformation of anatase to rutile, as discussed in detail below. Using the diffusion coefficient data for Ti measured in diopside (Cherniak and Liang, 2012), we calculate diffusion distances of $\sim 1 \mathrm{~nm}$ in 60 seconds at $1250^{\circ} \mathrm{C}$ using the expression $x \approx \sqrt{D t}$, where $x=$ distance in meters, $D$ is the diffusion coefficient $\left(\mathrm{m}^{2} \mathrm{~s}^{-1}\right)$, and $t$ is time (seconds). The development of diffusion profiles comparable in length to those observed in the diopside rim, i.e., few micrometers (Fig. 8), requires a timescale on the order of years. This timescale is not compatible with the preservation of $\mathrm{TiO}_{2}$ nanoparticles of intergrown rutile and anatase, as discussed in detail below. Therefore, we interpret the steeper zoning profile of $\mathrm{Ti}$ as being indicative of more rapid depletion of $\mathrm{Ti}$ in the gas phase compared with $\mathrm{Al}$, rather than the result of diffusional processes.

\subsection{Disequilibrium Formation Processes}

Implicit in the discussion above is the concept that the refractory CAI-like objects in AOA 02 experienced a complex thermal history that involved an initial stage of formation of the core by equilibrium condensation, followed by a later stage of reaction with the nebular gas that produced the fine-grained intergrowth layer that surrounds the cores of the objects. As noted earlier, it seems likely that spinel and melilite in the cores of the refractory CAI-like objects formed by equilibrium condensation processes as proposed by previous studies of AOAs (e.g., Grossman and Steele, 1976). However, after the initial period of condensation, we propose that conditions changed significantly and were followed by a dynamic period when reactions occurred under conditions that departed from equilibrium. The following observations provide evidence of disequilibrium conditions during the formation of the intergrowth layers on each of the CAI-like objects: i) the highly embayed and curved interfaces between refractory phases, particularly diopside and spinel; ii) the fine-grained nature of refractory phases in the intergrowth layers of the objects; iii) the common occurrence of Al-Ti-rich diopside without any association with perovskite and its extreme compositional variations over very short distances, i.e., microns; iv) the rarity of anorthite; and v) the presence of $\mathrm{TiO}_{2}$ nanoparticles consisting of a disordered intergrowth of anatase and rutile.

There are two plausible scenarios to explain how disequilibrium conditions could be achieved following the formation of the cores of the CAI-like objects, spinel and melilite: condensation in a super-cooled nebular gas (Wood, 2004; Petaev and Wood, 2005) or transport into a region of the solar nebula that is only partially condensed (Ciesla, 2010; Simon et al., 2011; Boss et al., 2012). Wood (2004) and Petaev and Wood (2005) discussed processes that may occur when the nebular gas undergoes rapid cooling. Under these conditions, equilibrium condensation is inhibited and the typical condensation sequence of refractory solids does not occur. However, once condensation commences, disequilibrium, metastable behavior is expected and textural and chemical equilibrium of condensation products is not likely to be attained. Due to incomplete condensation of high-temperature minerals from a super-cooled nebular gas, the ambient gas could be enriched in refractory elements, such as $\mathrm{Ti}, \mathrm{Al}$, and $\mathrm{Ca}$, which would be incorporated into Al-Ti-rich diopside once condensation starts (Petaev and Wood, 2005). Thus, rapid, disequilibrium condensation from a super-cooled nebular gas would have produced the observed reaction textures in the intergrowth layer and the large compositional variations in 
diopside. However, it is questionable about how these characteristics could have acquired with formation in a single gaseous reservoir that is undergoing cooling and a continuum of condensation processes that commenced with the formation of spinel and melilite under conditions that appear to have closely approached equilibrium. Further investigation for condensation processes from a super-cooled nebular gas is needed.

Disequilibrium conditions could also be achieved by rapid transport and injection of the primary condensate solids (i.e., spinel and melilite that constitute the cores of the CAI-like objects in AOA 02) into a region of the solar nebula that has undergone only partial condensation. Ciesla (2010) modeled the transport of high-temperature solids in a viscously evolving protoplanetary disk and Boss et al. (2012) calculated the trajectories of 0.1-10 cm-sized particles in a marginally gravitationally unstable solar nebula during an FU Orionis outburst. Despite differences in how transport occurs in the protoplanetary disk in their models, both the Ciesla (2010) and Boss et al. (2012) calculations show that individual particles move inward and outward in the disk repeatedly and consequently are exposed to a wide range of nebular density, pressure, and temperature conditions. In addition, the Ciesla (2010) and Boss et al. (2012) calculations estimate relatively short timescales for transport to have occurred in $\sim 10^{5}$ and $\sim 200$ years, respectively. These models therefore suggest that evidence of dynamic and rapidly changing conditions should be the norm for early-formed nebular solids. We propose that such transport within the disk on relatively short timescales, possibly $\sim 10^{2}-10^{5}$ years, can lead to changes from equilibrium to disequilibrium conditions which are recorded in the CAI-like objects in AOA 02. Boss et al. (2012) found that in their calculations particles were reintroduced into regions of the disk with ambient temperatures ranging from $1,550 \mathrm{~K}$ to $60 \mathrm{~K}$. A CAI that is transported into a region of the nebula with temperatures at the upper end of this range may be out of equilibrium with the ambient gas and would therefore undergo reactions with the gas phase. In Boss et al. (2012), the highest nebular temperatures encountered by a CAI lie within the calculated temperature ranges where diopside starts to condense from the nebular gas $\left(<1,480 \mathrm{~K}\right.$ at $10^{-3} \mathrm{~atm}$ in Ebel, 2006). Boss et al. (2012) also calculated the trajectories and consequent thermal histories of $1 \mathrm{~cm}$-sized refractory solids consisting of a melilite core surrounded by an icy mantle. These calculations show that the primary textural, chemical, and isotopic characteristics of the core were preserved throughout the evolution of the object due to the short duration of exposure to high temperatures, even though the icy mantle was lost and regained repeatedly.

The textural and chemical characteristics of AOA 02 require a two-stage history that seems to be compatible with the dynamic transport models proposed by Boss (2008), Ciesla (2010), and Boss et al. (2012). Figure 13 summarizes schematically how refractory CAI-like objects in AOA 02 experienced complex formational and thermal histories. This involved an initial stage in which formation of the cores of the refractory CAI-like objects consisting of spinel and \pm minor melilite occurred under relatively static conditions by equilibrium condensation. Spinel and \pm minor melilite formed by high-temperature equilibrium condensation from the nebular gas, forming compact core assemblages by aggregation, followed by subsequent annealing at high temperature to produce the equilibrium microstructures observed in the cores. At some later stage, probably following cooling to lower temperatures, these spinelrich cores were transported into a region of the nebular gas which was only partially condensed and still contained $\mathrm{Ti}$ and $\mathrm{Ca}$ in the gas phase. Under these conditions, the spinel and melilite in the cores were out of equilibrium with the gas and these conditions promoted the rapid condensation of Al-Ti-rich diopside by reactions with spinel and melilite. One problem with this 
model is the issue of why Al-Ti-rich diopside, rather than perovskite, forms in the reaction. One possible explanation for this behavior is that the formation of Al-Ti-rich diopside is favored because the reactions occurred out of equilibrium at a relatively lower temperature and $\mathrm{Mg}$ (and Al) was already present as a condensed phase in spinel in the cores of the CAI-like objects. These two factors may have favored a reaction path that formed a Ti-rich, Mg-bearing silicate phase (i.e., diopside), rather than hibonite, grossite, or perovskite, as Ca condensed from the gas phase. The short duration of the reactions resulted in both chemical and textural disequilibrium in the intergrowth layer, but allowed the preservation of the equilibrium textures in the spinelrich cores of the objects. As the reactions proceeded, spinel was isolated from the nebular gas by the formation of the layer of Al-Ti-rich diopside that zoned progressively into diopside with much lower $\mathrm{Al}$ and $\mathrm{Ti}$ contents. We attribute this reduction in $\mathrm{Al}$ and $\mathrm{Ti}$ contents in the diopside over a short distance to the isolation of the spinel from the gas phase as the reaction layer increased in thickness and the depletion of $\mathrm{Ti}$ in the gas phase.

\subsection{Origin of $\mathrm{TiO}_{2}$ Nanoparticles}

A new and important observation in this study is the occurrence of the $20-180 \mathrm{~nm}$-sized $\mathrm{TiO}_{2}$ nanoparticles within FIB D (Fig. 9). This FIB section is from S1 where regions of Al-Tirich diopside are interfingered with spinel (Fig. 2a). Previously, rutile inclusions have been reported by Greshake et al. (1998) in three Type A CAIs from the Acfer 082, Acfer 086, and Allende CV3 chondrites and in one spinel-perovskite spherule from the Acfer 094 carbonaceous chondrite. The $\mathrm{TiO}_{2}$ nanoparticles in AOA 02 share some textural similarities with the rutile inclusions in CAIs described by Greshake et al. (1998), but there are also significant differences. For example, rutile inclusions from the CAIs studied by Greshake et al. (1998) are located along grain boundaries between spinel grains and between spinel and perovskite grains. They are rarely found within the interior of spinel or perovskite grains and have no associations with melilite or Al-Ti-rich diopside. In this study, we have found $\mathrm{TiO}_{2}$ nanoparticles that occur only at grain boundaries between spinel grains and between spinel and Al-Ti-rich diopside grains, but no associations with perovskite or melilite are present (Fig. 9). In addition, the $\mathrm{TiO}_{2}$ nanoparticles in AOA 02 show clear crystallographic orientation relationships with neighboring spinel grains (Fig. 12), but there are no similar crystallographic orientation relationships of rutile inclusions in CV3 CAIs to the adjacent phases (Greshake et al., 1998). Lastly, an important difference is that $\mathrm{TiO}_{2}$ inclusions in CV3 CAIs are single crystals of rutile (Greshake et al., 1998), whereas the $\mathrm{TiO}_{2}$ nanoparticles in AOA 02 are disordered intergrowths of rutile and anatase (Fig. 11), the first documented occurrence of this feature in extraterrestrial samples. To our knowledge, the intergrowth of these two $\mathrm{TiO}_{2}$ polymorphs is also unknown in terrestrial samples as well. In this section, we first discuss possible formation mechanisms for the $\mathrm{TiO}_{2}$ nanoparticles and then examine the origin of the disordered intergrowth of anatase and rutile.

Two major mechanisms for the formation of the $\mathrm{TiO}_{2}$ nanoparticles in AOA 02 appear to be viable: exsolution from either Al-Ti-rich diopside or spinel or condensation from the nebular gas. The $\mathrm{TiO}_{2}$ nanoparticles may have exsolved from Al-Ti-rich diopside grains during cooling. Aluminum-Ti-rich diopside grains associated with the $\mathrm{TiO}_{2}$ nanoparticles in FIB D contain elevated $\mathrm{TiO}_{2}$ contents ranging from $8.4 \mathrm{wt} \%$ to $13 \mathrm{wt} \%$ (Fig. 7) and would be a potential source of $\mathrm{TiO}_{2}$ which might exsolve along grain boundaries. However, in detail we consider that exsolution from Al-Ti-rich diopside is unlikely. Exsolution reactions forming oxide phases within silicate minerals commonly result in crystallographic orientation relationships between the host and exsolved phases (e.g., Champness, 1970). We have not found any evidence of a 
crystallographic orientation relationship between the $\mathrm{TiO}_{2}$ nanoparticles and Al-Ti-rich diopside. Instead, there is a crystallographic orientation relationship between the $\mathrm{TiO}_{2}$ nanoparticles and spinel (Fig. 12). In addition, not all $\mathrm{TiO}_{2}$ nanoparticles occur along grain boundaries with Al-Tirich diopside; some $\mathrm{TiO}_{2}$ nanoparticles occur between spinel grains that are not in contact with any Al-Ti-rich diopside grain (Fig. 9b). Alternatively, the $\mathrm{TiO}_{2}$ nanoparticles could have exsolved from spinel, as is suggested by the crystallographic orientation relationship between the two phases (Fig. 12). The spinel grains in AOA 02 contain maximum $\mathrm{TiO}_{2}$ contents of 0.31 wt $\%$ with an average composition of $0.22 \mathrm{wt} \% \mathrm{TiO}_{2}$. If exsolution has occurred, the $\mathrm{TiO}_{2}$ contents of spinel would obviously have to be higher prior to exsolution, requiring that more $\mathrm{Ti}$ was incorporated into spinel at high temperatures. However, it seems unlikely that spinel that formed by high-temperature condensation retains enough $\mathrm{Ti}$ to exsolve $\mathrm{TiO}_{2}$, due to very low solubility of Ti in spinel (Connolly and Burnett, 2003). Further, exsolution also requires that a solvus exists between $\mathrm{MgAl}_{2} \mathrm{O}_{4}$ and $\mathrm{TiO}_{2}$. However, the phase diagram for the $\mathrm{MgO}-\mathrm{Al}_{2} \mathrm{O}_{3}-\mathrm{TiO}_{2}$ system shows that there is no binary join between $\mathrm{MgAl}_{2} \mathrm{O}_{4}$ and $\mathrm{TiO}_{2}$ at temperatures of $900-3,000 \mathrm{~K}$ (Kaufman, 1988), showing that $\mathrm{MgAl}_{2} \mathrm{O}_{4}$ and $\mathrm{TiO}_{2}$ do not coexist in this system. $\mathrm{MgAl}_{2} \mathrm{O}_{4}$ does form a continuous solid solution with $\mathrm{Mg}_{2} \mathrm{TiO}_{4}$ at high temperatures above $1,380^{\circ} \mathrm{C}$, but undergoes exsolution below $1,380^{\circ} \mathrm{C}$ to form $\mathrm{MgAl}_{2} \mathrm{O}_{4}, \mathrm{Mg}_{2} \mathrm{TiO}_{4}$, and $\mathrm{MgAl}_{2} \mathrm{O}_{4}-\mathrm{Mg}_{2} \mathrm{TiO}_{4}$ solid solution (Petrova et al., 1997). Therefore, if $\mathrm{TiO}_{2}$-bearing $\mathrm{MgAl}_{2} \mathrm{O}_{4}$ did form at high temperatures in AOAs, exsolution of $\mathrm{Mg}_{2} \mathrm{TiO}_{4}$, rather than $\mathrm{TiO}_{2}$, would be expected. Such relationships are not present in AOA02. Furthermore, to initiate exsolution of $\mathrm{Mg}_{2} \mathrm{TiO}_{4}$ from $\mathrm{MgAl}_{2} \mathrm{O}_{4}$ at $900^{\circ} \mathrm{C}$, the starting spinel solid solution must contain more than $10 \mathrm{~mol} \% \mathrm{Mg}_{2} \mathrm{TiO}_{4}$ (Petrova et al., 1997). Spinel with elevated $\mathrm{TiO}_{2}$ contents has never been reported from CAIs and AOAs in other carbonaceous chondrites, as well as ALHA77307. A further argument against an origin by exsolution from spinel is that the $\mathrm{TiO}_{2}$ nanoparticles are heterogeneously distributed along the grain boundaries in FIB D. Many grain boundaries adjacent to spinel are free of nanoparticles, indicating that the processes that formed the $\mathrm{TiO}_{2}$ nanoparticles acted in a heterogeneous manner. This is not consistent with an exsolution process, where incoherent interfaces such as grain boundaries are energetically favorable sites for nucleation, because of the lower activation energy for nucleation. In conclusion, exsolution of the $\mathrm{TiO}_{2}$ nanoparticles from either Al-Ti-rich diopside or $\mathrm{TiO}_{2}$-bearing spinel seems highly improbable.

An alternative formation mechanism is that the $\mathrm{TiO}_{2}$ nanoparticles are the product of high-temperature condensation from the cooling solar nebula. Equilibrium condensation calculations (Ebel, 2006) predict that $\mathrm{TiO}_{2}$ would not condense from a nebular gas because perovskite condenses as the first Ti-bearing mineral at higher temperatures and removes all the Ti from the gas. However, as discussed above, we propose that Al-Ti-rich diopside formed by the back-reaction of spinel and/or melilite with a partially condensed Ti-saturated gas, under conditions that depart significantly from equilibrium. We suggest that direct condensation of metastable $\mathrm{TiO}_{2}$ nanoparticles onto the surface of spinel grains may be viable under such disequilibrium conditions where kinetic effects may play a significant role in controlling the formation of phases. If the Al-Ti-rich diopside formed by rapid interaction with a partially condensed gas that still contains significant $\mathrm{Ti}$, condensation of more complex oxide phases such as perovskite may be inhibited, because $\mathrm{Ti}$ is incorporated into Al-Ti-rich diopside. Under such conditions, very rapid condensation of any excess $\mathrm{Ti}$ in the gas directly into simple oxide phases may be favored or condensation of both Al-Ti-rich diopside and $\mathrm{TiO}_{2}$ nanoparticles could have occurred simultaneously. Energetically this process could be aided by epitaxial nucleation and growth of the $\mathrm{TiO}_{2}$ nanoparticles onto spinel as indicated by the crystallographic orientation 
relationship between the $\mathrm{TiO}_{2}$ nanoparticles and spinel (Fig. 12). This mechanism may also explain why the $\mathrm{TiO}_{2}$ nanoparticles are heterogeneously distributed along the grain boundaries. Crystallographically-oriented $\mathrm{TiO}_{2}$ nanoparticle formation on spinel may only have occurred on exposed surfaces with the appropriate atomic structure to allow epitaxial nucleation and growth. If the $\mathrm{TiO}_{2}$ nanoparticles did form at high temperatures during disequilibrium condensation, their survival demonstrates that this process was rapid and was followed by extremely fast cooling. The very high surface free energies of such nanoparticles make them highly susceptible to grain growth; slow cooling would have resulted in coarsening of the nanoparticles. Their preservation also indicates that the CAI-like objects could not have been reheated for any significant time at high temperatures, for similar reasons. Similarly, Greshake et al. (1998) argued that rutile inclusions represent primary condensed solids that survived from the high-temperature melting events that formed compact Type A CAIs.

We next consider the origin and significance of the intergrowth of anatase and rutile in the $\mathrm{TiO}_{2}$ nanoparticles. Titanium dioxide, $\mathrm{TiO}_{2}$, occurs as three polymorphs, brookite, rutile and anatase. Rutile is the only stable $\mathrm{TiO}_{2}$ polymorph, but other $\mathrm{TiO}_{2}$ phases including anatase are metastable phases (e.g., Hanaor and Sorrell, 2011). Rutile is thermodynamically more stable than anatase because rutile has a lower free energy of formation than anatase at all temperatures under standard pressure (JANAF Thermochemical Tables), although the difference in the free energies of formation of the two polymorphs is small, $6.14 \mathrm{~kJ} / \mathrm{mol}$ at $298.15 \mathrm{~K}$. Anatase therefore transforms exothermally and irreversibly to rutile when heated. The transformation of anatase to rutile does not have a distinct equilibrium temperature at $1 \mathrm{~atm}$, but the reported temperatures vary in the range of $400-1,200^{\circ} \mathrm{C}$ (Hanaor and Sorrell, 2011). Penn and Banfield (1999) conducted hydrothermal heating treatments on nanocrystalline anatase $(\sim 5 \mathrm{~nm}$ in diameter $)$ at temperatures of $100-250^{\circ} \mathrm{C}$ for $1-255$ hours, followed by cooling in air. They observed that rutile nuclei four-unit cells in width grew within twinned anatase crystals, which was interpreted as representing partial transformation of anatase into rutile. Moreover, Gouma and Mills (2001) investigated the microstructural evolution of anatase-based $\mathrm{TiO}_{2}$ powder with a size range of 70$200 \mathrm{~nm}$ by heating at a rate of $10^{\circ} \mathrm{C} / \mathrm{min}$ to a peak temperature of $1,000^{\circ} \mathrm{C}$ for $3-24$ hours followed by cooling down to room temperature at a rate of $20^{\circ} \mathrm{C} / \mathrm{min}$. They found that partiallytransformed anatase particles contain a lamellar region consisting of fine rutile laths (plates) within an anatase matrix. This lamellar texture was interpreted as being the typical microstructure of a two-phase particle at the early stages of transformation. The nanostructures observed in these studies of synthetic samples have significant similarities to the fine-scale intergrowths of anatase and rutile found in this study (Figs. 11a and 11b). We thus suggest that the striated nanostructures we have found in the $\mathrm{TiO}_{2}$ nanoparticles in AOA 02 resulted from the anatase-to-rutile transformation as a result of heating at high temperatures.

When it occurs as nanoparticles, anatase can become thermodynamically more stable than rutile due to the size dependence of the thermodynamic stability fields of anatase and rutile (Zhang and Banfield, 1998; 2000). This relative change in stability field occurs when the anatase particle size is > 15 nm (Zhang and Banfield, 1998; 2000). Gribb and Banfield (1997) measured the average size of anatase nanoparticles that contain the first-detectable evidence of transformation to rutile after heating. They found that rutile starts to form after anatase nanoparticles have reached the average size of $\sim 14 \mathrm{~nm}$. This process occurs over a wide range of temperature and time, very consistent with the thermodynamic analysis of Zhang and Banfield $(1998,2000)$. These studies suggest that whatever their formation mechanism, the $\mathrm{TiO}_{2}$ nanoparticles in AOA 02 nucleated as anatase and then started to transform into rutile after the 
anatase nanoparticles grew to a critical size. For free-standing nanoparticles, this size is $\sim 14 \mathrm{~nm}$, but this value may be different when the nanoparticles have interfaces with adjacent phases and interfacial energies contribute to the overall energetics of the system. Once the anatase-to-rutile transformation has started, grain growth of both polymorphs occurs simultaneously (Gribb and Banfield, 1997; Ding and Liu, 1998; Gouma and Mills, 2001). For example, experimental heating of anatase crystals ( $\sim 6 \mathrm{~nm}$ in diameter) at temperatures between $465-525^{\circ} \mathrm{C}$ produced an increase in the average grain size of rutile and percent transformation to rutile with both time and temperature and a linear correlation between transformation rate and coarsening rate of anatase (Gribb and Banfield, 1997). Kinetic studies of the anatase-to-rutile transformation show that it proceeds very rapidly once the transformation has started (Shannon and Pask, 1965; Gribb and Banfield, 1997; Ding and Liu, 1998; Gouma and Mills, 2001). Gouma and Mills (2001) showed that 70-200 nm-sized anatase particles fully transform into rutile in 8 hours when heated in air at $1,000^{\circ} \mathrm{C}$. The transformation rate also does appear to be affected by the environmental conditions. Shannon and Pask (1965) showed a difference in the rate of anatase-to-rutile transformation when anatase is heated at $1,017^{\circ} \mathrm{C}$ in air and in vacuum. The transformation rate in vacuum follows that in air up to $\sim 30 \%$ of the transformation reaction and then rapidly decreases. Therefore, if the $\mathrm{TiO}_{2}$ nanoparticles formed in the solar nebula under pressure conditions that are generally considered to lie in the range of $\sim 10^{-4}$ to $6 \times 10^{-6}$ bars, the transformation rate may be somewhat slower.

We have found the crystallographic orientation relationship between intergrown anatase and rutile in the $\mathrm{TiO}_{2}$ nanoparticles in AOA 02 (Figs. 11c and 11d) as: [111] rutile // [131 $]_{\text {anatase }}$ and $(1 \overline{1} 0)_{\text {rutile }} / /(10 \overline{1})_{\text {anatase }}$ For this orientation relationship, the following planes are also parallel:

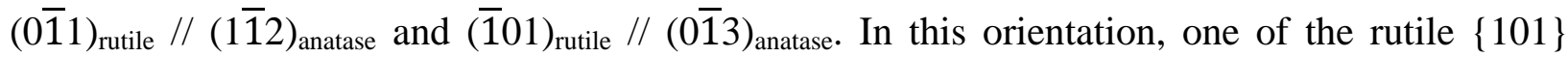
planes (the twin plane in rutile) lies parallel to the (112) twin plane of anatase. Based on experimental observations and theoretical analysis of the structural relationships between anatase and rutile, the predicted crystallographic orientation relationship between the two phases should be with the $\{112\}$ pseudo-close-packed oxygen planes in anatase parallel to the $\{100\}$ pseudoclose-packed oxygen planes in rutile (Shannon and Pask, 1965). This is also the orientation relationship for the transformation observed by Gouma and Mills (2001) and reported by Penn and Banfield (1999), based on an experimental study of the anatase to rutile transformation in $\mathrm{TiO}_{2}$ nanoparticles. Our data are not consistent with these observations, however, and indicate a different orientation relationship that does not have the close-oxygen planes in the two phases parallel. Interestingly, the electron diffraction data presented by Penn and Banfield (1999) suggest that the orientation relationship that they obtained between the two phases is, in fact, the same as the one that we have found in this study. However, contrary to their electron diffraction data, they assigned the twin plane in rutile to the (010) plane, rather than (101), the known twin plane in rutile. A detailed analysis of the mechanism of the anatase to rutile phase transformation is beyond the scope of this paper, but the available data seem to indicate that two mechanisms are possible for the anatase to rutile transformation that result in different orientation relationships; one that exhibits a high degree of topotaxy between the two structures and one where the retention of some of the structural elements of anatase in rutile is lower.

As discussed above, our favored scenario for the formation of the $\mathrm{TiO}_{2}$ nanoparticles is metastable condensation from the nebular gas under disequilibrium conditions. The experimental data discussed above indicate that anatase would have been the stable polymorph that nucleated, but that as anatase grains grew transformation to rutile would have started once a critical nanoparticle size was reached. Spinel and diopside start to condense from the gas phase at 
temperatures below $1200^{\circ} \mathrm{C}$ at $10^{-3}$ atm (Ebel, 2006). Therefore, the $\mathrm{TiO}_{2}$ nanoparticles in $\mathrm{AOA}$ 02 must have formed at similar temperatures. Based on data for the rate of the anatase to rutile transformation (Shannon and Pask, 1965; Gouma and Mills, 2001), complete transformation of anatase to rutile at high temperatures would have occurred on very short timescales. For example, Gouma and Mills (2001) found that anatase nanoparticles completely transform to rutile in 8 hours at $1,000^{\circ} \mathrm{C}$. Although there is currently no detailed kinetic analysis of the anatase to rutile transformation, based on the exponential dependence of transformation rates on temperature, we estimate that at $1,200^{\circ} \mathrm{C}$ complete transformation is likely to occur on timescales of the order of minutes. Therefore, the incomplete transformation of anatase to rutile recorded in the $\mathrm{TiO}_{2}$ nanoparticles requires that the duration of exposure of the refractory CAI-like objects to elevated temperatures must have been extremely short and have been followed by very rapid cooling to arrest the complete transformation of anatase to rutile.

\section{CONCLUSIONS}

Our SEM and TEM observations of refractory CAI-like objects in AOA 02 from the ALHA77307 CO3.0 chondrite reveal that the CAI-like objects in the AOA record a complex formational and thermal history. The spinel-rich cores of the CAI-like objects consist of polycrystalline aggregates of spinel and minor melilite with equilibrated grain boundary textures, indicating formation under equilibrium conditions. However, the inner layers between the cores and diopside rims exhibit very complex intergrowths of fine-grained diopside, spinel, and minor anorthite, commonly with curved and embayed grains boundaries. The compositions of diopside in the intergrowth layer show remarkable variations, notably in $\mathrm{Al}_{2} \mathrm{O}_{3}$ and $\mathrm{TiO}_{2}$ contents over very short distances $(\leq \sim 2 \mu \mathrm{m})$. The highest $\mathrm{Al}_{2} \mathrm{O}_{3}$ and $\mathrm{TiO}_{2}$ contents occur adjacent to spinel and partially reacted melilite in the cores of the refractory objects. The microstructural and chemical characteristics of the intergrowth layers suggest that they formed under highly disequilibrium conditions. We propose that these features are the result of transport of the refractory objects into a region of partially-condensed gas that resulted in the rapid reaction of melilite and spinel with a $\mathrm{Ca}$,Ti-saturated gas to form Al-Ti-rich diopside.

The local presence of crystallographically-oriented $\mathrm{TiO}_{2}$ nanoparticles along grain boundaries between spinel grains and between spinel and Al-Ti-rich diopside grains is interpreted as being indicative of rapid epitaxial nucleation and growth under disequilibrium conditions. The disequilibrium back-reaction of spinel with a $\mathrm{Ca}$,Ti-saturated gas initiated the condensation of metastable $\mathrm{TiO}_{2}$ nanoparticles at the same time as the formation of Al-Ti-rich diopside. These nanoparticles are disordered intergrowths of two $\mathrm{TiO}_{2}$ polymorphs, anatase and rutile, the first reported occurrence of such an intergrowth in a natural sample, either terrestrial or extraterrestrial. Based on experimental studies of the behavior of anatase nanoparticles, we infer that these $\mathrm{TiO}_{2}$ nanoparticles nucleated as the $\mathrm{TiO}_{2}$ polymorph anatase that underwent only partial transformation to rutile. This requires that the thermal event which caused the disequilibrium back-reaction of the spinel and melilite with the gas was extremely short-lived and was followed by rapid cooling to prevent complete transformation of anatase to rutile.

Finally, the compositional profile for Ti in the Al-Ti pyroxene layer is steeper than that for $\mathrm{Al}$, suggesting that $\mathrm{Ti}$ is depleted from the gas phase faster than Al. This difference in behavior of $\mathrm{Al}$ and $\mathrm{Ti}$ cannot be attributed to differences in diffusion rates for these two elements, because experimental diffusion data show that their diffusivities are comparable. In addition, the extremely slow rates of diffusion of both elements preclude development of zoning 
profiles on timescales that are compatible for the preservation of $\mathrm{TiO}_{2}$ nanoparticles that consist of intergrowths of rutile and anatase.

\section{ACKNOWLEDGEMENT}

We thank Dr. Tim Fagan, Dr. Alex Ruzicka, and Dr. Steve Simon for their thoughtful and constructive reviews of the manuscript and Dr. Sara Russell for her comments and editorial handling of the manuscript. The technical assistance with the electron microprobe analysis from Mike Spilde and for FIB and TEM works from Dr.Ying-Bing Jiang is greatly appreciated. Electron microbeam analysis was carried out in the Electron Microbeam Analysis Facility, Department of Earth and Planetary Sciences and Institute of Meteoritics at the University of New Mexico. The facility is supported by funds from the State of New Mexico, the National Science Foundation, and NASA. This work was supported by NASA's Cosmochemistry Program through grants NNG06GG37G and NNX12AH59G to Adrian Brearley (P.I). 


\section{REFERENCES}

Bonal L., Bourot-Denise M., Quirico E., Montagnac G. and Lewin E. (2007) Organic matter and metamorphic history of CO chondrites. Geochim. Cosmochim. Acta 71, 1605-1623.

Boss A. P. (2008) Mixing in the solar nebula: Implications for isotopic heterogeneity and large-scale transport of refractory grains. Earth Planet. Sci. Lett. 268, 102-109.

Boss A. P., Alexander C. M.O'D. and Podolak M. (2012) Cosmochemical consequences of particle trajectories during FU Orionis outbursts by the early Sun. Earth Planet. Sci. Lett. 345-348, 18-26.

Bullock E. S. and MacPherson G. J. (2009) A pristine amoeboid olivine aggregate protolith from the Vigarano CV3 chondrite. Lunar Planet. Sci. 40, \#2385 (abstr.).

Champness P. E. (1970) Nucleation and growth of iron oxides in olivines. Mineralogical magazine 37, 790-800.

Cherniak D.J. and Liang Y. (2012) Ti diffusion in natural pyroxene. Geochim. Cosmochim. Acta 98, 3147.

Chizmadia L. J., Rubin A. E. and Wasson J. T. (2002) Mineralogy and petrology of amoeboid olivine inclusions in $\mathrm{CO} 3$ chondrites: Relationship to parent-body aqueous alteration. Meteorit. Planet. Sci. 37, 1781-1796.

Ciesla F. J. (2010) The distributions and ages of refractory objects in the solar nebula. Icarus 208, 455467.

Connolly A. C. and Burnett D. S. (2003) On type B CAI formation: Experimental constraints on $f \mathrm{O}_{2}$ variations in spinel minor element partitioning and reequilibration effects. Geochim. Cosmochim. Acta 67, 4429-4434.

Deer W. A., Howie R. A. and Zussman J. (1992) An introduction to the rock-forming minerals (2nd Edition). pp. 548-551.

Ding X. and Liu X. (1998) Correlation between anatase-to-rutile transformation and grain growth in nanocrystalline titania powders. J. Mater. Res. 13, 2556-2559.

Ebel D. S. (2006) Condensation of rocky material in astrophysical environments. In Meteorites and the Early Solar System II (eds. D. S. Lauretta and H. Y. McSween). Univ. of Arizona Press, Tucson. pp. 253-277.

El Goresy A., Zinner E., Matsunami S., Palme H., Spettel B., Lin Y. and Nazarov M. (2002) Efremovka 101.1: A CAI with ultrarefractory REE patterns and enormous enrichments of Sc, $\mathrm{Zr}$, and $\mathrm{Y}$ in fassaite and perovskite. Geochim. Cosmochim. Acta 66, 1459-1491.

Fagan T. J., Krot A. N., Keil K. and Yurimoto H. (2004) Oxygen isotopic compositions of amoeboid olivine aggregates in the reduced CV3 chondrites Efremovka, Vigarano and Leoville. Geochim. Cosmochim. Acta 68, 2405-2611.

Gouma P. I. and Mills M. J. (2001) Anatase-to-rutile transformation in titania powders. J. Am. Ceram. Soc. 84, 619-622. 
Greshake A., Bischoff A. and Putnis A. (1998) Transmission electron microscope study of compact Type A calcium-aluminum-rich inclusions from CV3 chondrites: Clues to their origin. Meteorit. Planet. Sci. 33, 75-87.

Gribb A. A. and Banfield J. F. (1997) Particle size effects on transformation kinetics and phase stability in nanocrystalline $\mathrm{TiO}_{2}$. Am. Miner. 82, 717-728.

Grossman J. N. and Brearley A. J. (2005) The onset of metamorphism in ordinary and carbonaceous chondrites. Meteorit. Planet. Sci. 40, 87-122.

Grossman L. and Steele I. M. (1976) Amoeboid olivine aggregates in the Allende meteorite. Geochim. Cosmochim. Acta 40, 149-155.

Grossman L., Ganapathy R., Methot R. L. and Davis A. M. (1979) Trace elements in the Allende meteorite-IV. Amoeboid olivine aggregates. Geochim. Cosmochim. Acta 43, 817-829.

Han J. (2014) Microstructural constraints on the formational and thermal histories of refractory inclusions in CO3 chondrites. Ph.D. thesis, Univ. of New Mexico.

Han J. and Brearley A. J. (2011a) Amoeboid olivine aggregates from the ALHA 77307 CO3.0 chondrite: Microstructural constraints on the origin of refractory components. Lunar Planet. Sci. 42, \#1673 (abstr.).

Han J. and Brearley A. J. (2011b) Formation of $\mathrm{TiO}_{2}$ nanoparticles in a CAI-like object from an AOA in the ALHA 77307 CO3.0 carbonaceous chondrite. Meteorit. Planet. Sci. 46 (Suppl.), \#5190 (abstr.).

Han J. and Brearley A. J. (2015) Microstructural evidence for complex formation histories of amoeboid olivine aggregates from the ALHA77307 CO3.0 chondrite. Meteorit. Planet. Sci. 50, 904-925.

Han J., Keller L. P., Needham A. W., Messenger S. and Simon J. I. (2015) Microstructural investigation of a Wark-Lovering rim on a Vigarano CAI. 78th annual meteoritical society meeting, \#5243 (abstr.)

Hanaor D. A. and Sorrell C. C. (2011) Review of the anatase to rutile phase transformation. J. Mater. Sci. 46, 855-874.

Hashimoto A. and Grossman L. (1987) Alteration of Al-rich inclusions inside amoeboid olivine aggregates in the Allende meteorite. Geochim. Cosmochim. Acta 51, 1685-1704.

Itoh S., Rubin A. E., Kojima H., Wasson J. T. and Yurimoto H. (2002) Amoeboid olivine aggregates and AOA-bearing chondrule from Y-81020 CO 3.0 chondrite: Distribution of oxygen and magnesium isotopes. Lunar Planet. Sci. 33, \#1490 (abstr.).

Kaufman L. (1988) Calculation of multicomponent ceramic phase diagrams. Physica B 150, 99-114.

Keller L. P., Needham A. W. and Messenger S. (2013) A FIB/TEM study of a complex Wark-Lovering rim on a Vigarano CAI. 76th annual meteoritical society meeting, \#5300 (abstr.)

Kimura M., Grossman J. N. and Weisberg M. K. (2008) Fe-Ni metal in primitive chondrites: Indicators of 
classification and metamorphic conditions for ordinary and CO chondrites. Meteorit. Planet. Sci. 43, 1161-1177.

Kimura M., Mikouchi T., Suzuki A., Miyahara M., Ohtani E. and El Goresy A. (2009) Kushiroite, $\mathrm{CaAlAlSiO}_{6}$ : A new mineral of the pyroxene group from the $\mathrm{ALH} 85085 \mathrm{CH}$ chondrites, and its genetic significance in refractory inclusions. Am. Miner. 94, 1479-1482.

Komatsu M., Krot A. N., Petaev M. I., Ulyanov A. A., Keil K. and Miyamoto M. (2001) Mineralogy and petrography of amoeboid olivine aggregates from the reduced CV3 chondrites Efremovka, Leoville and Vigarano: Products of nebular condensation and accretion. Meteorit. Planet. Sci. 36, 629-643.

Komatsu M., Mikouchi T. and Miyamoto M. (2009) High-temperature annealing of amoeboid olivine aggregates: Heating experiments on olivine-anorthite mixtures. Polar Science 3, 31-55.

Krot A. N., Petaev M. I., Russell S. S., Itoh S., Fagan T., Yurimoto H., Chizmadia L., Weisberg M. K., Komatsu M., Ulyanov A. A. and Keil K. (2004a) Amoeboid olivine aggregates in carbonaceous chondrites: Records of nebular and asteroidal processes. (Invited review). Chem. Erde 64, 185239.

Krot A. N., Petaev M. I. and Yurimoto H. (2004b) Amoeboid olivine aggregates with low-Ca pyroxenes: A genetic link between refractory inclusions and chondrules? Geochim. Cosmochim. Acta 68, 1923-1941.

Krot A. N., Petaev M. I., Fagan T. J. and Yurimoto H. (2004c) Ca,Al-rich inclusions, amoeboid olivine aggregates and Al-rich chondrules from the unique carbonaceous chondrite Acfer 094: I. Mineralogy and petrology. Geochim. Cosmochim. Acta 68, 2167-2184.

Krot A. N., Fagan T. J., Nagashima K., Petaev M. I. and Yurimoto H. (2005) Origin of low-Ca pyroxene in amoeboid olivine aggregates: Evidence from oxygen isotopic compositions. Geochim. Cosmochim. Acta 69, 1873-1881.

Lin Y., Kimura M. and Wang D. (2003) Fassaites in compact type A Ca-Al-rich inclusions in the Ningqiang carbonaceous chondrite: Evidence for partial melting in the nebula. Meteorit. Planet. Sci. 38, 407-417.

MacPherson G. J. and Davis A. M. (1994) Refractory inclusions in the prototypical CM chondrite, Mighei. Geochim. Cosmochim. Acta 58, 5599-5625.

MacPherson G. J., Grossman L., Beckett J. R. and Allen J. M. (1981) Origin of rims on coarse-grained inclusions in the Allende meteorite. Proc. Lunar Planet. Sci. Conf. 12B, 1079-1091.

Penn R. L. and Banfield J. F. (1999) Formation of rutile nuclei at anatase $\{112\}$ twin interfaces and the phase transformation mechanism in nanocrystalline titania. Am. Miner. 84, 871-876.

Petaev M. I. and Wood J. A. (2005) Meteoritic constraints on temperatures, pressures, cooling rates, chemical compositions, and modes of condensation in the solar nebula. In Chondrites and Protoplanetary Disk (eds. A. N. Krot, E. R. D. Scott and B. Reipurth). ASP Conference Series Vol. 341. pp.373-406.

Petrova M. A., Mikirticheva G. A., Novikova A. S. and Popova V. F. (1997) Spinel solid solutions in the 
systems $\mathrm{MgAl}_{2} \mathrm{O}_{4}-\mathrm{ZnAl}_{2} \mathrm{O}_{4}$ and $\mathrm{MgAl}_{2} \mathrm{O}_{4}-\mathrm{Mg}_{2} \mathrm{TiO}_{4}$. J. Mater. Res. 12, 2584-2588.

Rubin A. E. (1998) Correlated petrologic and geochemical characteristics of CO3 chondrites. Meteorit. Planet. Sci. 33, 385-391.

Rubin A. E. (2007) Petrography of refractory inclusions in CM2.6 QUE 97990 and the origin of melilitefree spinel inclusions in CM chondrites. Meteorit. Planet. Sci. 42, 1711-1726.

Russell S. S., Huss G. R., Fahey A. J., Greenwood R. C., Hutchison R. and Wasserburg G. J. (1998) An isotopic and petrologic study of calcium-aluminum-rich inclusions from $\mathrm{CO} 3$ meteorites. Geochim. Cosmochim. Acta 62, 689-714.

Ruzicka A. (1997) Mineral layers around coarse-grained, Ca-Al-rich inclusions in CV3 carbonaceous chondrites: Formation by high-temperature metasomatism. J. Geophys. Res. 102, 13387-13402.

Ruzicka A., Floss C. and Hutson M. (2012) Amoeboid olivine aggregates (AOAs) in the Efremovka, Leoville and Vigarano (CV3) chondrites: A record of condensate evolution in the solar nebula. Geochim. Cosmochim. Acta 79, 79-105.

Sautter V., Jaoul O. and Abel F. (1988) Aluminium diffusion in diopside using the 27Al(p, c)28Si nuclear reaction: preliminary results. Earth Planet. Sci. Lett. 89, 109-114.

Scott E. R. D. and Jones R. H. (1990) Disentangling nebular and asteroidal features of CO3 carbonaceous chondrite meteorites. Geochim. Cosmochim. Acta 54, 2485-2502.

Shannon R. D. and Pask J. A. (1965) Kinetics of the anatase-rutile transformations. J. Am. Ceram. Soc. 48, 391-398.

Simon J. I., Hutcheon I. D., Simon S. B., Matzel J. E. P., Ramon E. C., Weber P. K., Grossman L. G. and DePaolo D. J. (2011) Oxygen isotope variations at the margin of a CAI records circulation within the solar nebula. Science 331, 1175-1178.

Simon S. B., Sutton S. R. and Grossman L. (2007) Valence of titanium and vanadium in pyroxene in refractory inclusion interiors and rims. Geochim. Cosmochim. Acta 71, 3098-3118.

Wark D. and Boynton W. V. (2001) The formation of rims on calcium-aluminum-rich inclusions: Step I flash heating. Meteorit. Planet. Sci. 36, 1135-1166.

Wark D. and Lovering J. F. (1977) Marker events in the early evolution of the solar system: Evidence from rims on Ca-Al-rich inclusions in carbonaceous chondrites. Proc. Lunar Planet. Sci. Conf. 8, 95-112.

Weisberg M. K., Connolly H. C. and Ebel D. S. (2004) Petrology and origin of amoeboid olivine aggregates in CR chondrites. Meteorit. Planet. Sci. 39, 1741-1753.

Wood J. A. (2004) Formation of chondritic refractory inclusions: The astrophysical setting. Geochim. Cosmochim. Acta 68, 4007-4021.

Zega T. J., Simon S. B. and Grossman L. (2010) Microstructural analysis of a Wark-Lovering rim around an Allende CAI. 73rd annual meteoritical society meeting, \#5433 (abstr.) 
Zega T. J., Cosarinsky M., Stroud R. M. and McKeegan K. D. (2007) FIB-TEM study of a WarkLovering rim in an Allende Type-A CAI. 70th annual meteoritical society meeting, \#5289 (abstr.)

Zega T. J., Cosarinsky M., MacPherson G. J. and McKeegan K. D. (2009) FIB-TEM analysis on a WarkLovering rim from the Vigarano CV3 chondrite. 72nd annual meteoritical society meeting, \#5374 (abstr.)

Zhang A. and Hsu W. (2009) Refractory inclusions and aluminum-rich chondrules in Sayh al Uhaymir 290 CH chondrite: Petrography and mineralogy. Meteorit. Planet. Sci. 44, 787-804.

Zhang H. and Banfield J. F. (1998) Thermodynamic analysis of phase stability of nanocrystalline titania. J. Mater. Chem. 8, 2073-2076.

Zhang H. and Banfield J. F. (2000) Understanding Polymorphic Phase Transformation Behavior during Growth of Nanocrystalline Aggregates: Insights from $\mathrm{TiO}_{2}$. J. Phys. Chem. B 104, 3481-3487. 


\section{TABLE}

Table 1. Representative electron microprobe analyses of spinel, pyroxene, and olivine in AOA 02 from ALHA77307.

\begin{tabular}{|c|c|c|c|c|c|c|c|c|c|c|c|c|c|c|c|c|c|c|c|c|c|}
\hline \multirow[b]{2}{*}{ Object } & \multicolumn{7}{|l|}{ spinel } & \multicolumn{7}{|c|}{ Al-diospide } & Al-Ti- & \multicolumn{6}{|l|}{ olivine } \\
\hline & S1 & S2 & S3 & S3 & S3 & S4 & S4 & S2 & S2 & S3 & S3 & S3 & S4 & S4 & S4 & & & & & & \\
\hline $\mathrm{SiO}_{2}$ & 0.09 & 0.09 & 0.02 & bd & $\mathrm{bd}$ & bd & bd & 49.71 & 51.95 & 48.85 & 51.41 & 47.59 & 53.03 & 50.30 & 36.88 & 42.24 & 42.52 & 42.05 & 42.32 & 42.00 & 41.92 \\
\hline $\mathrm{TiO}_{2}$ & 0.38 & 0.09 & 0.09 & 0.07 & 0.07 & 0.08 & 0.09 & 0.21 & 0.14 & 1.64 & 0.97 & 1.92 & 0.35 & 0.33 & 7.36 & 0.00 & bd & bd & 0.01 & 0.01 & 0.00 \\
\hline $\mathrm{Al}_{2} \mathrm{O}_{3}$ & 72.13 & 72.45 & 70.71 & 70.95 & 70.94 & 70.94 & 70.86 & 7.46 & 4.21 & 8.71 & 6.00 & 10.55 & 3.56 & 8.02 & 21.39 & 0.05 & 0.00 & 0.07 & 0.02 & 0.02 & bd \\
\hline $\mathrm{V}_{2} \mathrm{O}_{3}$ & 0.29 & 0.30 & 0.16 & 0.18 & 0.18 & 0.17 & 0.18 & 0.02 & bd & 0.10 & 0.08 & 0.13 & 0.02 & 0.03 & 0.46 & nd & nd & nd & nd & nd & nd \\
\hline $\mathrm{Cr}_{2} \mathrm{O}_{3}$ & 0.27 & 0.10 & 0.07 & 0.07 & 0.10 & 0.11 & 0.12 & 0.04 & 0.03 & 0.07 & 0.06 & 0.09 & 0.03 & 0.04 & 0.08 & 0.07 & 0.11 & 0.05 & 0.07 & 0.08 & 0.10 \\
\hline $\mathrm{FeO}$ & 0.27 & 0.31 & 0.19 & 0.21 & 0.24 & 0.20 & 0.23 & 0.45 & 0.28 & 0.37 & 0.46 & 0.47 & 0.22 & 0.20 & 0.30 & 0.54 & 0.87 & 0.41 & 0.24 & 0.42 & 0.75 \\
\hline $\mathrm{MnO}$ & bd & 0.01 & bd & bd & bd & bd & bd & 0.00 & bd & 0.02 & 0.02 & 0.03 & bd & 0.01 & 0.00 & 0.03 & 0.14 & 0.02 & 0.03 & 0.03 & 0.01 \\
\hline $\mathrm{MgO}$ & 26.86 & 26.46 & 27.42 & 27.44 & 27.54 & 27.52 & 27.47 & 15.56 & 17.09 & 14.93 & 16.11 & 14.61 & 17.95 & 15.81 & 9.69 & 56.36 & 56.31 & 56.04 & 56.14 & 56.10 & 55.59 \\
\hline $\mathrm{CaO}$ & 0.09 & 0.08 & 0.14 & 0.08 & 0.09 & 0.04 & 0.04 & 25.02 & 24.51 & 25.22 & 25.08 & 24.48 & 24.70 & 25.15 & 24.26 & 0.13 & 0.09 & 0.33 & 0.18 & 0.14 & 0.18 \\
\hline $\mathrm{Na}_{2} \mathrm{O}$ & bd & bd & 0.01 & 0.01 & 0.02 & 0.02 & 0.01 & 0.02 & 0.01 & $\mathrm{bd}$ & $\mathrm{bd}$ & 0.01 & bd & 0.01 & 0.01 & 0.01 & 0.01 & 0.01 & 0.00 & 0.01 & bd \\
\hline $\mathrm{K}_{2} \mathrm{O}$ & 0.02 & 0.03 & bd & bd & bd & bd & 0.00 & 0.03 & 0.03 & 0.05 & 0.04 & 0.04 & 0.03 & 0.04 & 0.04 & nd & nd & nd & nd & nd & nd \\
\hline \multirow[t]{2}{*}{ Total } & 100.4 & 99.9 & 98.8 & 99.0 & 99.2 & 99.1 & 99.0 & 98.5 & 98.2 & 100.0 & 100.2 & 99.9 & 99.9 & 99.9 & 100.5 & 99.4 & 100.0 & 99.0 & 99.0 & 98.8 & 98.6 \\
\hline & \multicolumn{7}{|c|}{ Cations per 4 oxygen anions } & \multicolumn{8}{|c|}{ Cations per 6 oxygen anions } & \multicolumn{6}{|c|}{ Cations per 4 oxygen anions } \\
\hline $\mathrm{Si}$ & 0.002 & 0.002 & 0.001 & - & - & - & - & 1.825 & 1.905 & 1.772 & 1.854 & 1.726 & 1.913 & 1.817 & 1.349 & 0.998 & 1.000 & 0.998 & 1.003 & 0.998 & 1.000 \\
\hline $\mathrm{Ti}$ & 0.007 & 0.002 & 0.002 & 0.001 & 0.001 & 0.001 & 0.002 & 0.006 & 0.004 & 0.045 & 0.026 & 0.052 & 0.009 & 0.009 & 0.203 & - & - & - & - & - & - \\
\hline $\mathrm{Al}$ & 2.008 & 2.025 & 2.000 & 2.003 & 2.000 & 2.001 & 2.001 & 0.323 & 0.182 & 0.372 & 0.255 & 0.451 & 0.151 & 0.342 & 0.922 & 0.001 & - & 0.002 & 0.001 & - & - \\
\hline $\mathrm{V}$ & 0.006 & 0.006 & 0.003 & 0.003 & 0.004 & 0.003 & 0.004 & - & - & 0.003 & 0.002 & 0.004 & - & 0.001 & 0.014 & - & - & - & - & - & - \\
\hline $\mathrm{Cr}$ & 0.005 & 0.002 & 0.001 & 0.001 & 0.002 & 0.002 & 0.002 & 0.001 & 0.001 & 0.002 & 0.002 & 0.003 & 0.001 & 0.001 & 0.002 & 0.001 & 0.002 & 0.001 & 0.001 & 0.002 & 0.002 \\
\hline $\mathrm{Fe}$ & 0.005 & 0.006 & 0.004 & 0.004 & 0.005 & 0.004 & 0.005 & 0.014 & 0.009 & 0.011 & 0.014 & 0.014 & 0.007 & 0.006 & 0.009 & 0.011 & 0.017 & 0.008 & 0.005 & 0.008 & 0.015 \\
\hline $\mathrm{Mn}$ & - & - & - & - & - & - & - & - & - & 0.001 & 0.001 & 0.001 & - & - & - & 0.001 & 0.003 & 0.001 & 0.001 & 0.001 & - \\
\hline $\mathrm{Mg}$ & 0.946 & 0.935 & 0.981 & 0.980 & 0.982 & 0.982 & 0.981 & 0.852 & 0.935 & 0.807 & 0.866 & 0.790 & 0.965 & 0.852 & 0.528 & 1.985 & 1.974 & 1.982 & 1.982 & 1.988 & 1.977 \\
\hline $\mathrm{Ca}$ & 0.002 & 0.002 & 0.004 & 0.002 & 0.002 & 0.001 & 0.001 & 0.984 & 0.963 & 0.980 & 0.969 & 0.951 & 0.955 & 0.974 & 0.951 & 0.003 & 0.002 & 0.008 & 0.005 & 0.003 & 0.005 \\
\hline $\mathrm{Na}$ & - & - & 0.001 & 0.001 & 0.001 & 0.001 & 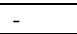 & 0.001 & 0.001 & - & - & - & - & 0.001 & 0.001 & 0.001 & - & - & - & - & - \\
\hline $\mathrm{K}$ & 0.001 & 0.001 & - & & - & - & - & 0.001 & 0.001 & 0.002 & 0.002 & 0.002 & 0.002 & 0.002 & 0.002 & & - & - & - & - & - \\
\hline Total & 2.982 & 2.981 & 2.996 & 2.995 & 2.997 & 2.996 & 2.995 & 4.008 & 4.001 & 3.996 & 3.991 & 3.994 & 4.002 & 4.004 & 3.980 & 3.001 & 2.999 & 3.001 & 2.997 & 3.001 & 2.999 \\
\hline & & & & & & & & & & & & & & & & & & & & & \\
\hline $\mathrm{Mg} \#$ & 0.5 & 0.6 & 0.4 & 0.4 & 0.5 & 0.4 & 0.5 & & & & & & & & & 0.6 & 0.9 & 0.4 & 0.3 & 0.4 & 0.8 \\
\hline
\end{tabular}




\section{FIGURE CAPTIONS}

Figure 1. BSE image (a) and combined X-ray maps in $\mathrm{Mg} \mathrm{K} \alpha$ (red), $\mathrm{Ca} \mathrm{K} \alpha$ (green), and $\mathrm{Al} \mathrm{K} \alpha$ (blue) (b) and in $\mathrm{Ti} \mathrm{K} \alpha$ (red), $\mathrm{Ca} \mathrm{K \alpha}$ (green), and $\mathrm{Al} \mathrm{K} \alpha$ (blue) (c) of AOA 02 from ALHA77307. The AOA consists of forsteritic olivine grains and zoned CAI-like objects. Minor $\mathrm{Fe}, \mathrm{Ni}$-metal grains are present. In (c), the designation of refractory CAI-like objects as S1 to S4 are indicated. mel $=$ melilite $; \mathrm{sp}=$ spinel; $\mathrm{px}=$ pyroxene; $\mathrm{ol}=$ olivine , met $=$ Fe,Ni-metal; $\mathrm{G}=$ gold coating residues.

Figure 2. BSE images of four refractory CAI-like objects in AOA 02. The CAI-like objects show a zonal sequence with a spinel-rich core enclosed by an inner layer of fine-grained intergrown spinel and Al-Ti-rich diopside rimmed by pure diopside. The dotted lines in (a) and (b) indicate the locations of four FIB sections prepared for this study.

Figure 3. DF-STEM images of melilite-rich regions in FIB A from S2. The melilite grains appear to be corroded by surrounding spinel and diopside grains and these textures indicate that melilite was replaced by spinel and diopside. The dotted lines are grain boundaries of different phases. AlTi-px $=$ Al-Ti-rich pyroxene with $>2 \mathrm{wt}^{2} \mathrm{TiO}_{2} ;$ Al-di $=$ Al-rich diopside with $\leq 2 \mathrm{wt} \% \mathrm{TiO}_{2}$.

Figure 4. Mosaic of DF-STEM images of FIB B from S2. This section shows a zonal sequence from the spinel core (right) through a complex intergrowth layer of fine-grained diopside, spinel and anorthite to the surrounding olivine (left) of AOA 02. Each phase is outlined by dotted lines of different colors; spinel is red, anorthite is blue, and olivine is yellow. The rest of the FIB section is occupied by diopside. The arrows indicate $120^{\circ}$ triple junctions between olivine and diopside at the left end of the section.

Figure 5. BF-TEM and DF-STEM images showing an intergrowth of spinel and diopside in the core regions of S1 from FIB C (a) and D (b). Note that the grain boundaries of these two phases are highly curved and embayed, indicating a reaction relationship between them.

Figure 6. BF-TEM images of the core regions of S1 from FIB C (a) and D (b). In (a) and (b), the core regions of the object consist of aggregates of spinel grains with minor diopside, commonly associated with straight grain boundaries and $120^{\circ}$ triple junction indicative of equilibrated textures. In (b), $\mathrm{TiO}_{2}$ nanoparticles occur along the grain boundaries between spinel grains and between spinel and diopside grains. The arrows indicate $120^{\circ}$ triple junctions between spinel and diopside.

Figure 7. A plot of $\mathrm{TiO}_{2}$ versus $\mathrm{Al}_{2} \mathrm{O}_{3}(\mathrm{wt} \%)$ in pyroxene from four FIB sections. The data are taken from TEM EDS analyses. Each analysis represents a single analytical point. Pyroxene having a range of $\mathrm{Al}_{2} \mathrm{O}_{3}$ contents from $0 \mathrm{wt} \%$ to $10 \mathrm{wt} \%$ shows uniform, very low $\mathrm{TiO}_{2}$ contents $\leq 1 \mathrm{wt} \%$. This compositional range occurs only in pyroxene from FIB B. In all the FIB sections, pyroxene has $\mathrm{Al}_{2} \mathrm{O}_{3}$ contents higher than $10 \mathrm{wt} \%$ which are positively correlated with $\mathrm{TiO}_{2}$ contents ranging from $0 \mathrm{wt} \%$ to $14 \mathrm{wt} \%$. The horizontal dotted line represents a cutoff of $2 \mathrm{wt} \%$ $\mathrm{TiO}_{2}$ to separate between Al-Ti-rich pyroxene and Al-rich diopside.

Figure 8. A plot of $\mathrm{TiO}_{2}$ and $\mathrm{Al}_{2} \mathrm{O}_{3}$ contents (wt $\%$ ) in pyroxene from FIB B along a traverse 
across the section. Data obtained by TEM EDS analyses, and each point represents a single analysis. The changes in $\mathrm{Al}_{2} \mathrm{O}_{3}$ contents of pyroxene occur progressively with increasing a distance from the interface with olivine $\left(0.5 \mathrm{wt} \% \mathrm{Al}_{2} \mathrm{O}_{3}\right)$ to the interface with the spinel-rich core (27 wt $\% \mathrm{Al}_{2} \mathrm{O}_{3}$ ). However, pyroxene has a relatively constant range of $\mathrm{TiO}_{2}$ contents $(\leq 1 \mathrm{wt} \%)$ through the middle of FIB B, but has $\mathrm{TiO}_{2}$ contents that increase significantly by $\sim 11 \mathrm{wt} \%$ over a very short distance $(\leq \sim 2 \mu \mathrm{m})$ towards the contact with the spinel-rich core. The vertical dotted lines represent boundaries that reflect three compositional zones of Al-Ti-poor, Al-rich Ti-poor, and Al-Ti-rich pyroxene towards the core.

Figure 9. BF-TEM (a) and DF-STEM (b, c) images of $\mathrm{TiO}_{2}$ nanoparticles from FIB D. In (a), the $\mathrm{TiO}_{2}$ nanoparticles (dark grains that are diffracting strongly) decorate the grain boundaries between diopside and spinel grains. In (b) and (c), the $\mathrm{TiO}_{2}$ nanoparticles (white grains) decorate the grain boundaries between spinel grains as well as between diopside and spinel.

Figure 10. TEM EDS spectrum (a) and EF-TEM O (b) and Ti (c) maps of a single $\mathrm{TiO}_{2}$ nanoparticle. (a) EDS spectra obtained from some of the nanoparticles by TEM EDS show that they contain only $\mathrm{Ti}$ and $\mathrm{O}$, although the small peaks for $\mathrm{Si}, \mathrm{Al}$, and $\mathrm{Mg}$ are present in the spectrum that are due to X-ray contributions from the surrounding phases, pyroxene and spinel. (b, c) EF-TEM elemental maps support the presence of pure Ti oxide.

Figure 11. TEM images (a, b) and FFT patterns (c, d) of the $\mathrm{TiO}_{2}$ nanoparticle shown in (b). (a) BF-TEM image showing the striated texture of the nanoparticle. (b) HR-TEM image of the $\mathrm{TiO}_{2}$ nanoparticle. The lattice fringes display disorder and twinning. (c, d) The FFT patterns obtained from (b) that show the complexity of the nanoparticles. The most intense diffraction maxima (red circles) can be indexed as the [111] zone axis of rutile and the weaker diffraction maxima (blue circles) as the [131] zone axis of anatase: [111] rutile // [131] $]_{\text {anatase }}$ and $(1 \overline{1} 0)_{\text {rutile }} / /(10 \overline{1})_{\text {anatase }}$. Reflections resulting from twinning on the (101) plane of rutile (yellow circles) are labeled on the FFT patterns. The twin plane is indicated by yellow dotted line in (c).

Figure 12. HR-TEM image (a) and FFT patterns (b, c) of $\mathrm{TiO}_{2}$ nanoparticles and neighboring spinel grains. (a) The lattice fringes of the $\mathrm{TiO}_{2}$ nanoparticles are parallel to those of the spinel grains. (b, c) The [010] zone axes of rutile nanoparticles are parallel to the [111] zone axis of spinel with $(100)_{\text {rutile }} / /(\overline{1} 01)_{\text {spinel. }}$ The nanoparticles are crystallographically-oriented relative to the spinel grains, suggesting that the $\mathrm{TiO}_{2}$ nanoparticles nucleated epitaxially onto spinel grains.

Figure 13. Schematic diagram illustrating the possible formational history of the refractory CAIlike objects in AOA 02. We suggest a generalized sequence to form the refractory CAI-like objects in the AOA as follows: stage 1: equilibrium condensation of spinel with minor melilite; stage 2: aggregation and annealing of early-formed equilibrium condensates; stage 3: transport and injection of primary equilibrium condensates into a region of a partially-condensed, $\mathrm{Ca}, \mathrm{Ti}$ saturated gas; stage 4: disequilibrium back-reaction of primary equilibrium condensates with the surrounding gas; stage 5: formation of Al-Ti-rich diopside; stage 6: progressive decrease of Al and $\mathrm{Ti}$ in pyroxene outwards; and stage 7: direct condensation of pure diopside as rims on the objects. 


\section{Figure 1}

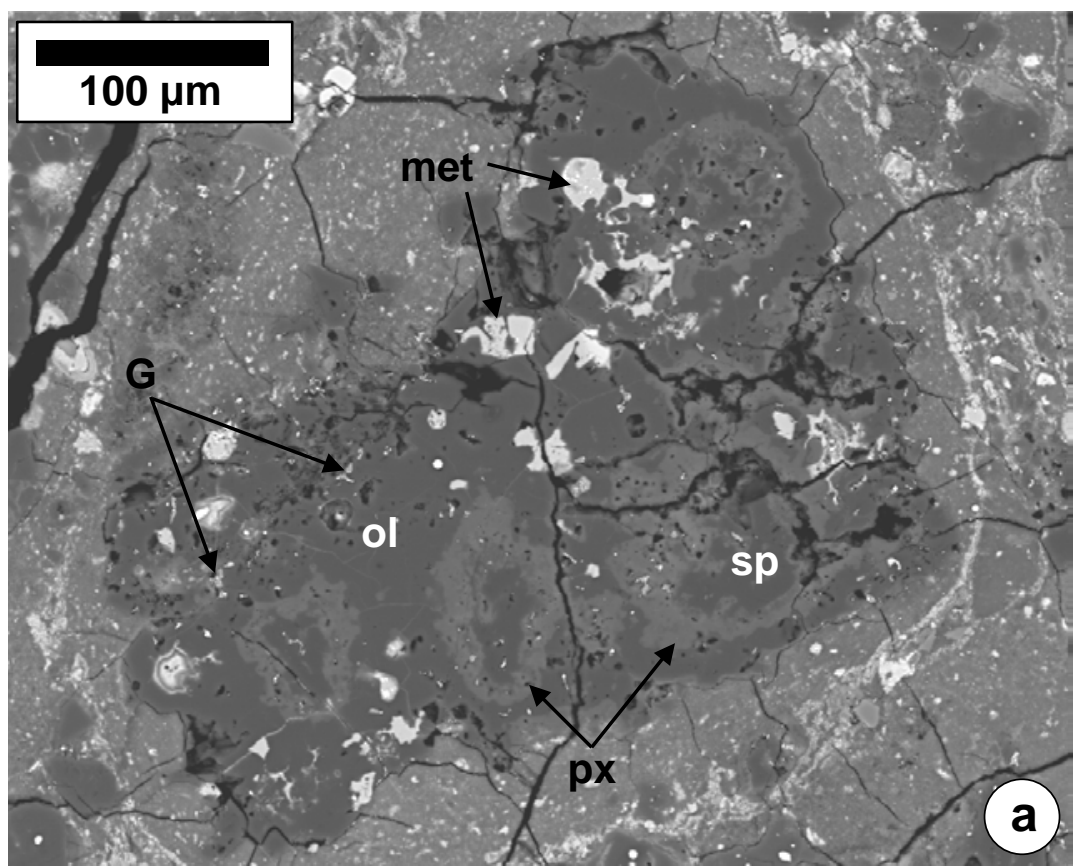

\section{Mg Ca Al}

Ti Ca Al

S1

ans

Exyst

Q -130
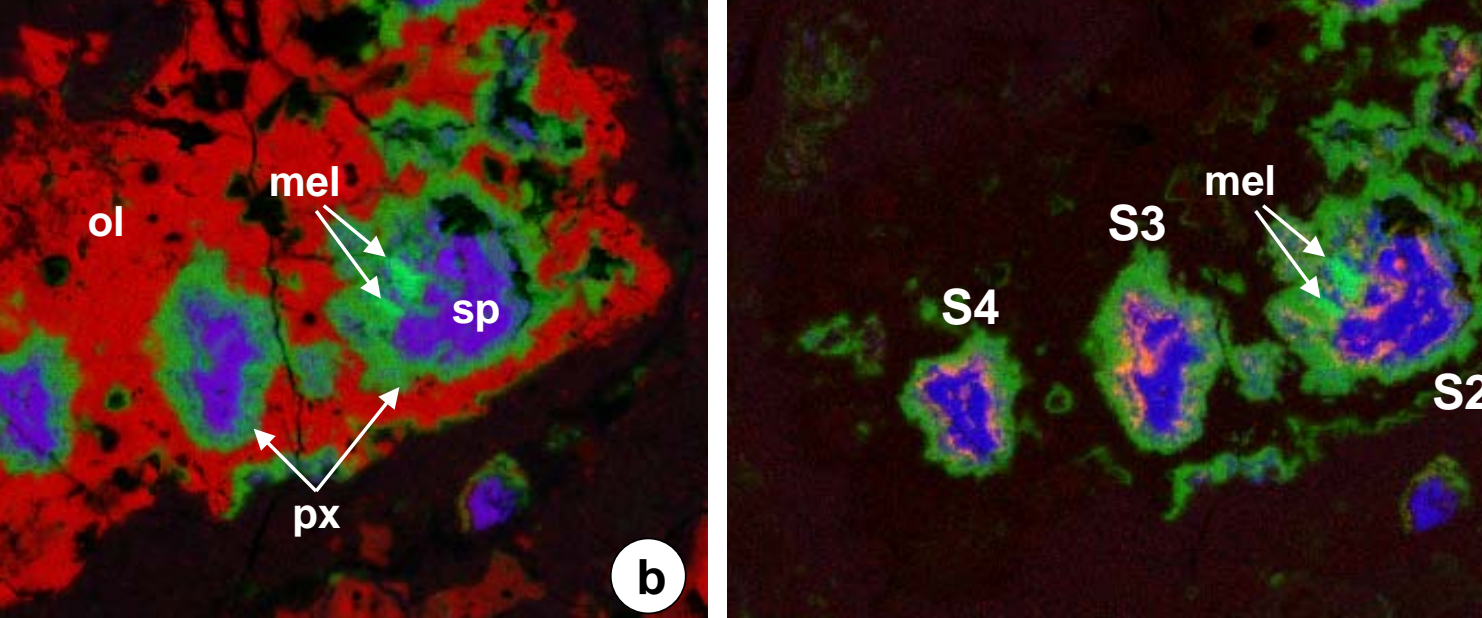

S2

c 


\section{Figure 2}

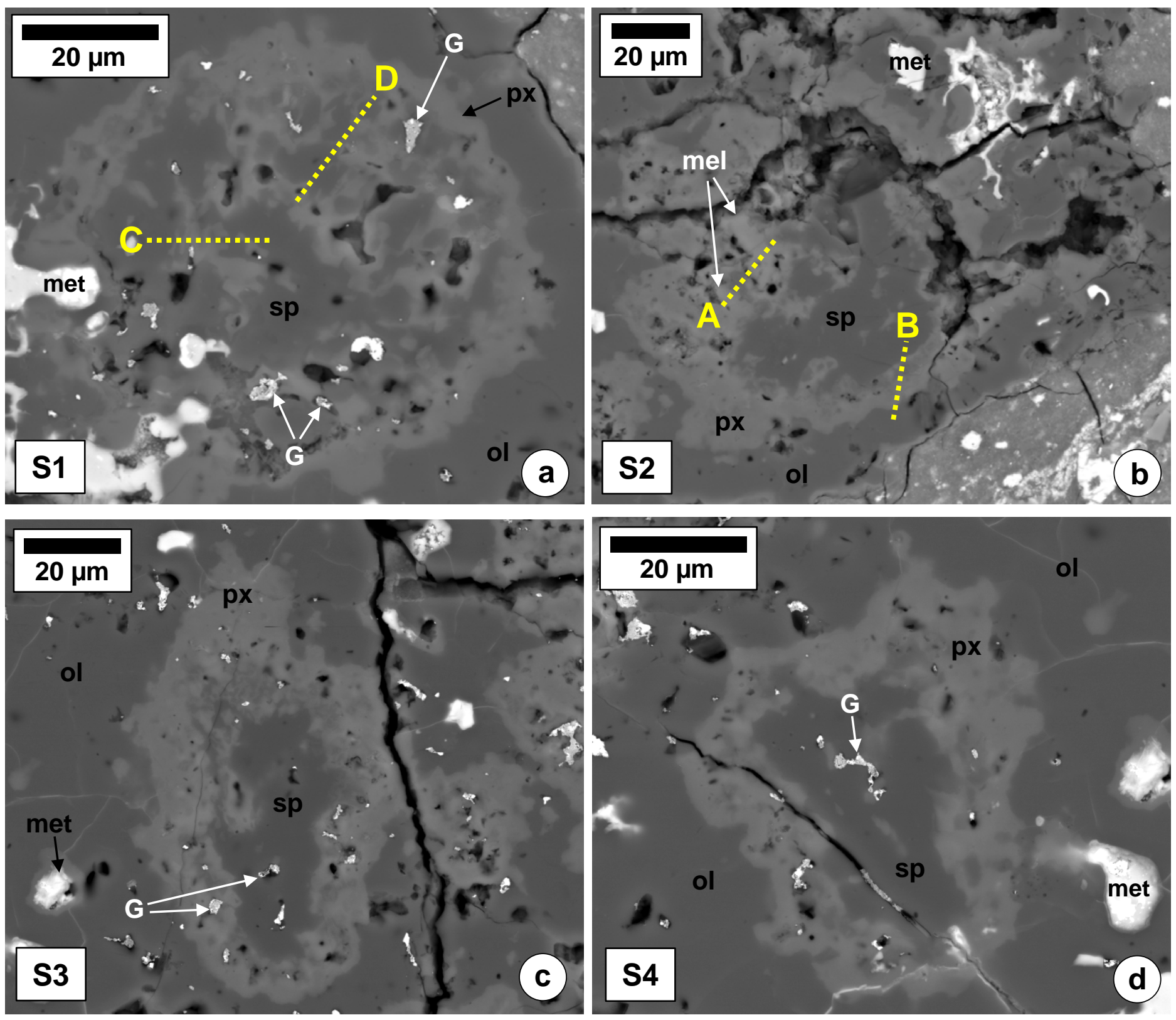




\section{Figure 3}

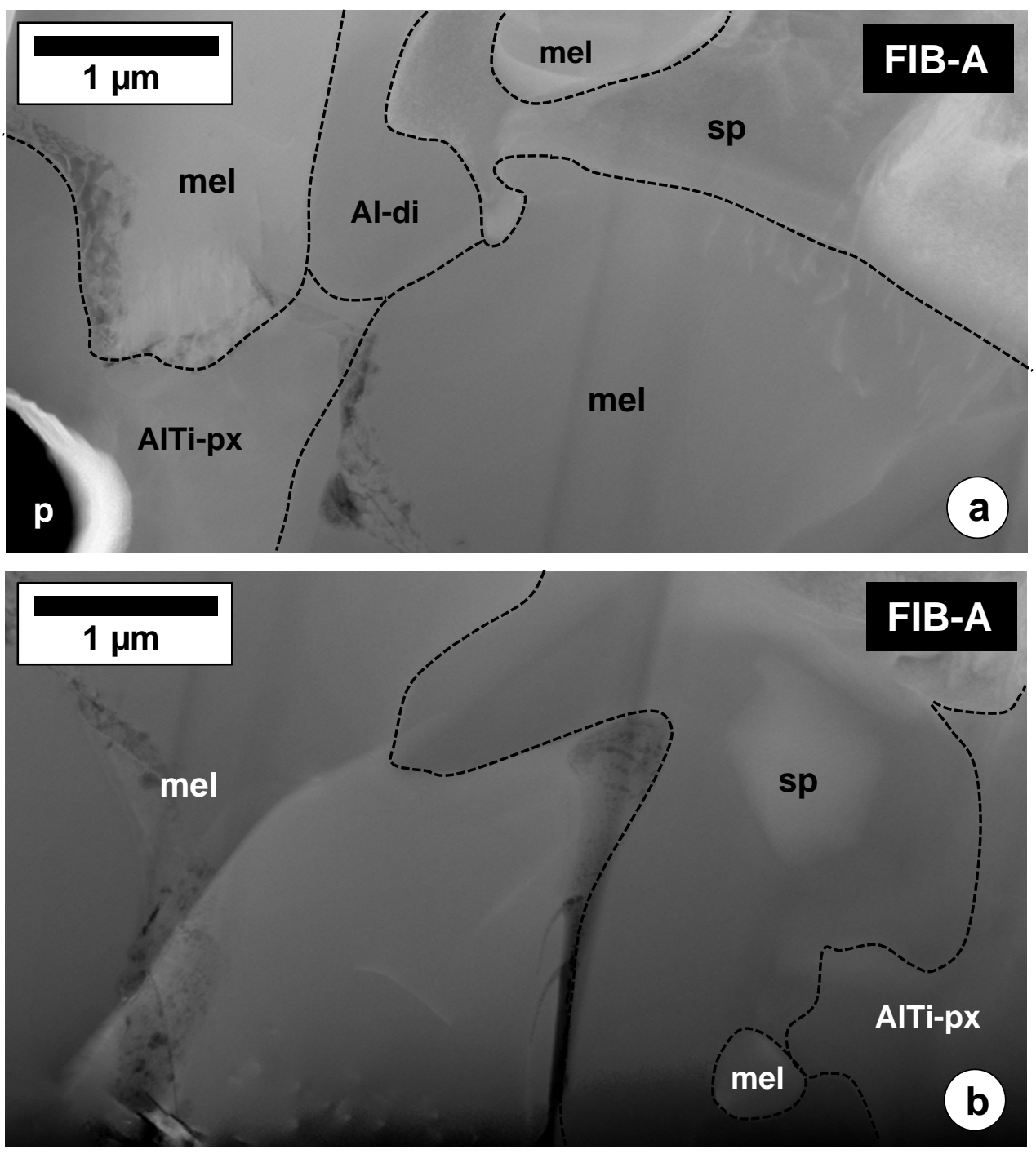




\section{Figure 4}

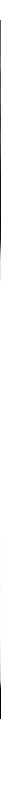




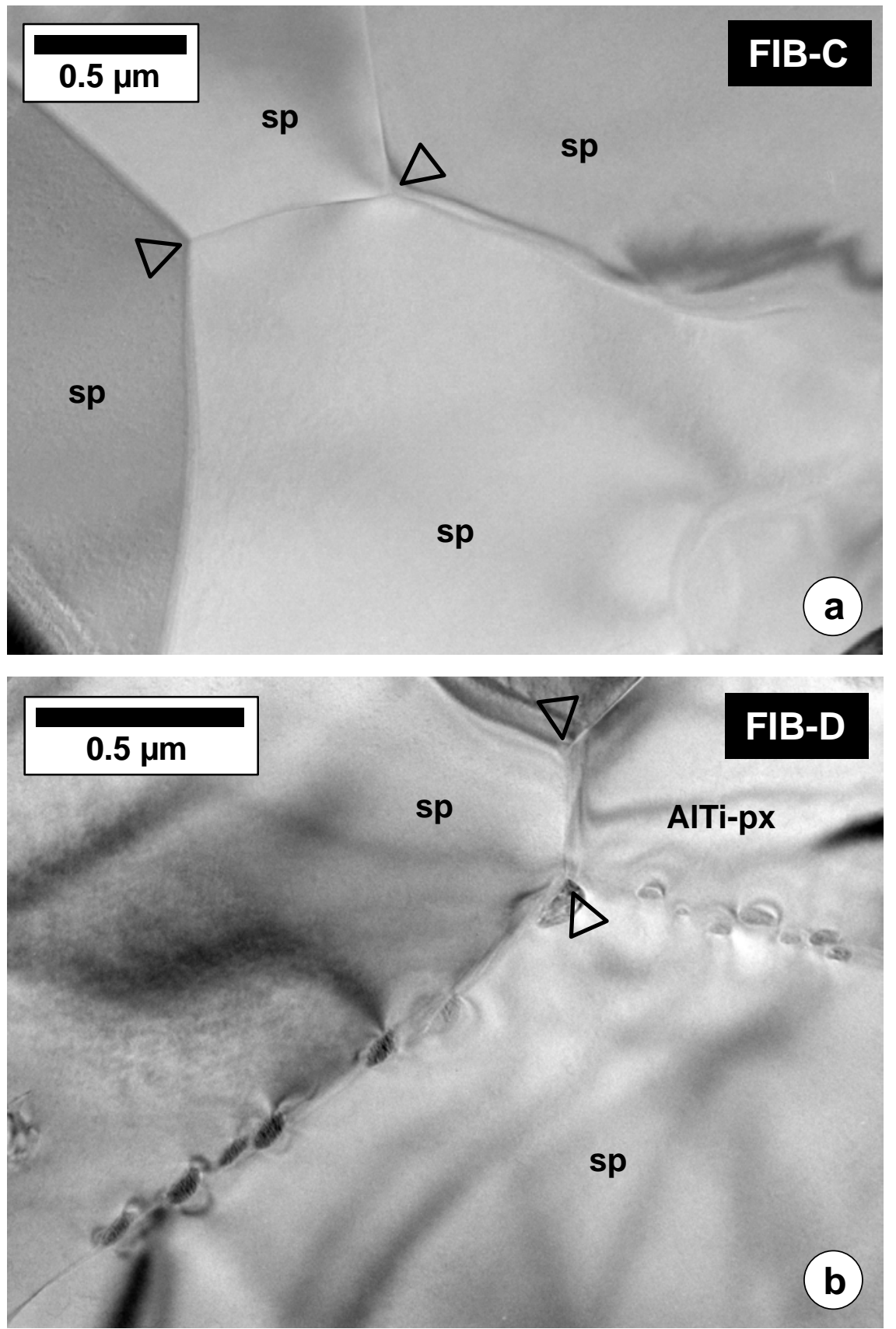




\section{Figure 6}

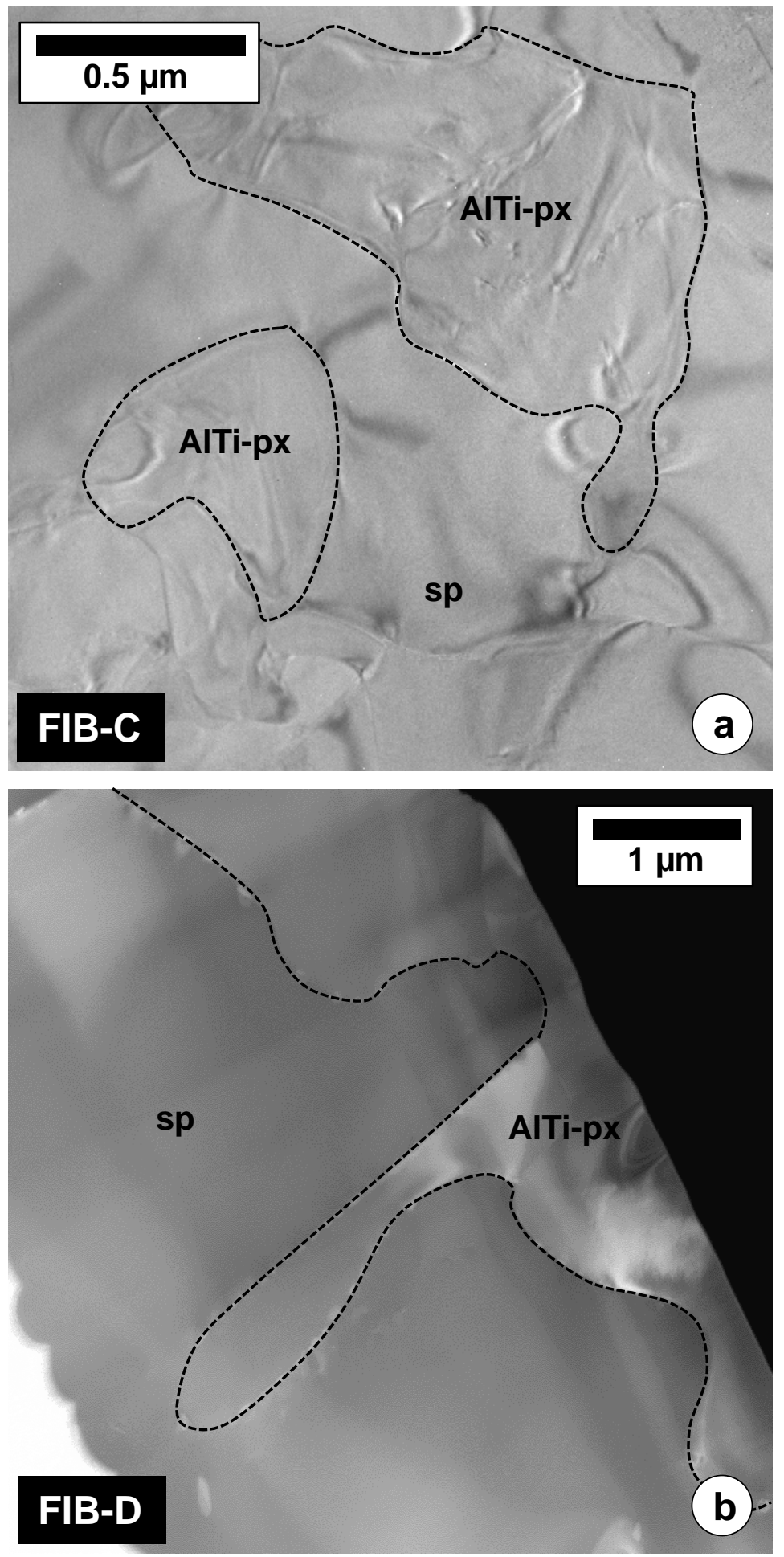




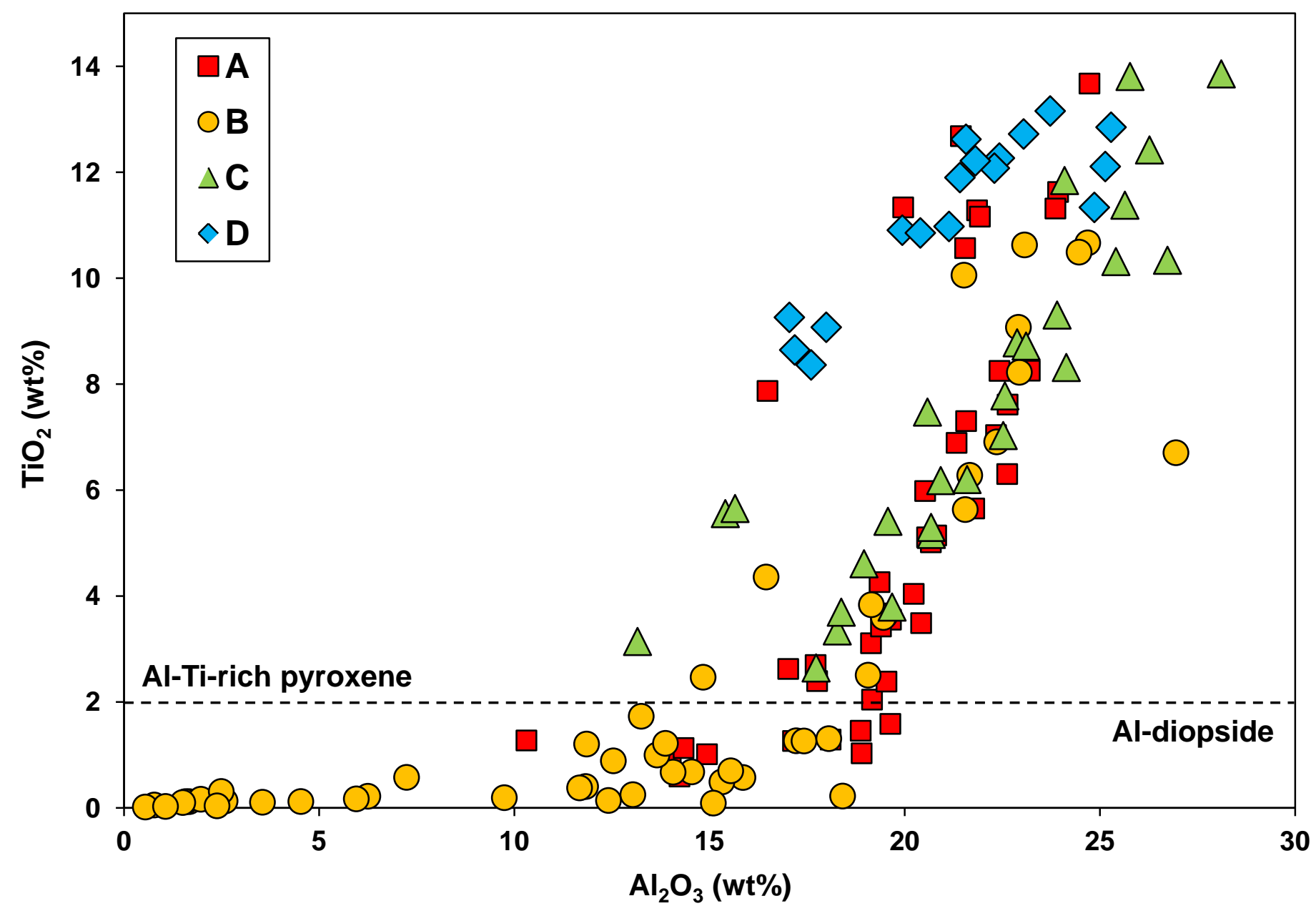


FIB B

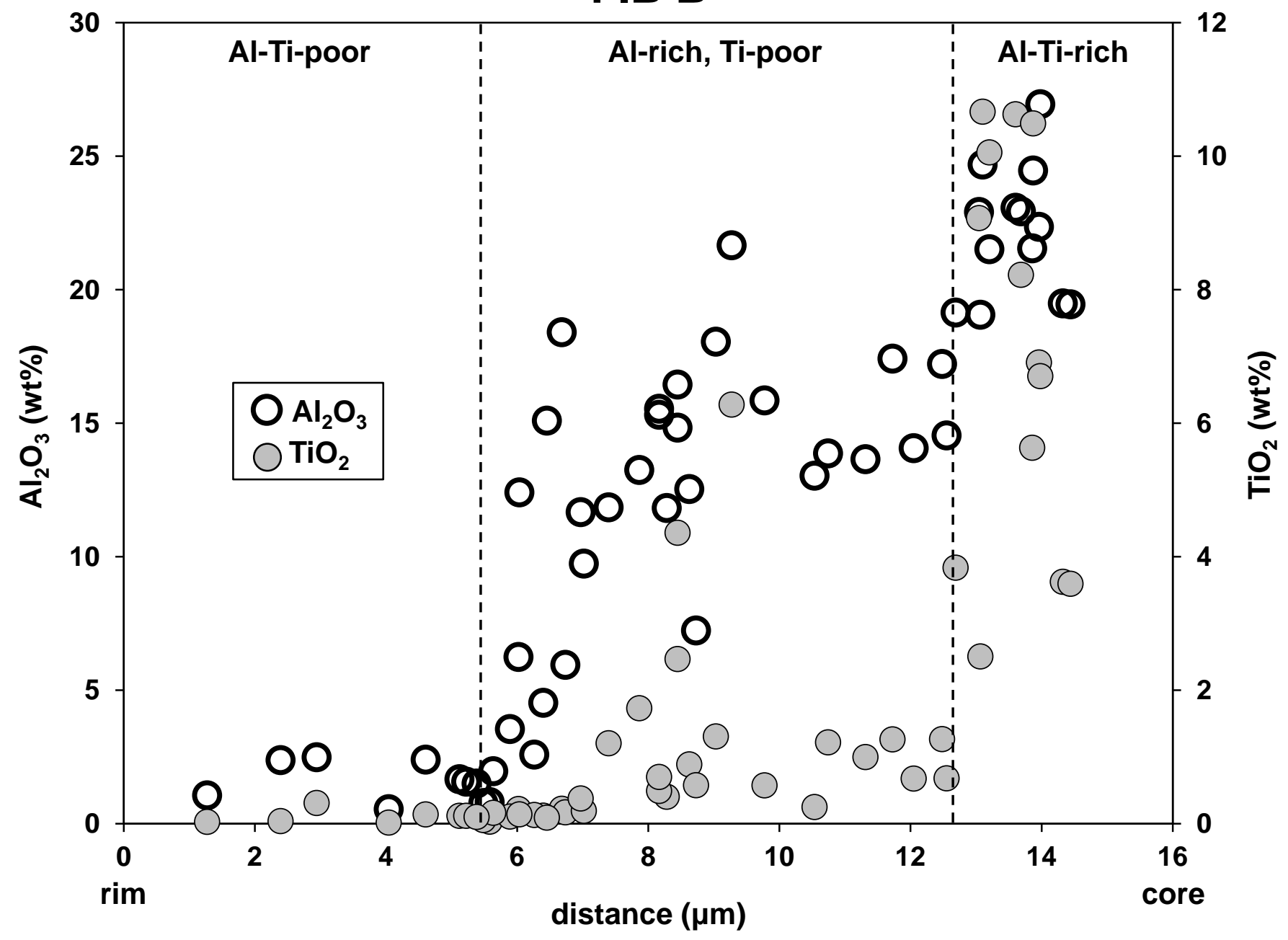



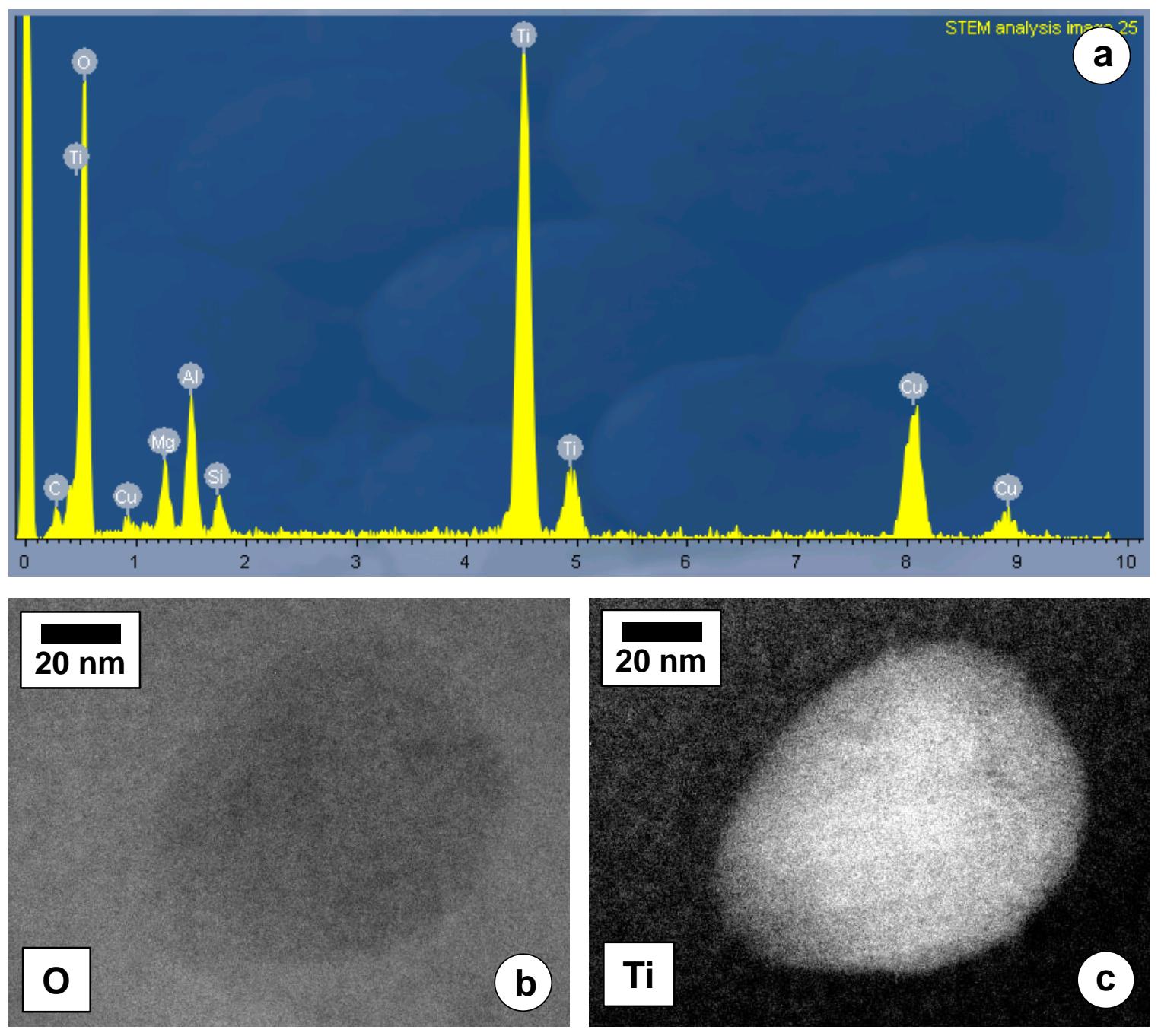


\section{Figure 11}
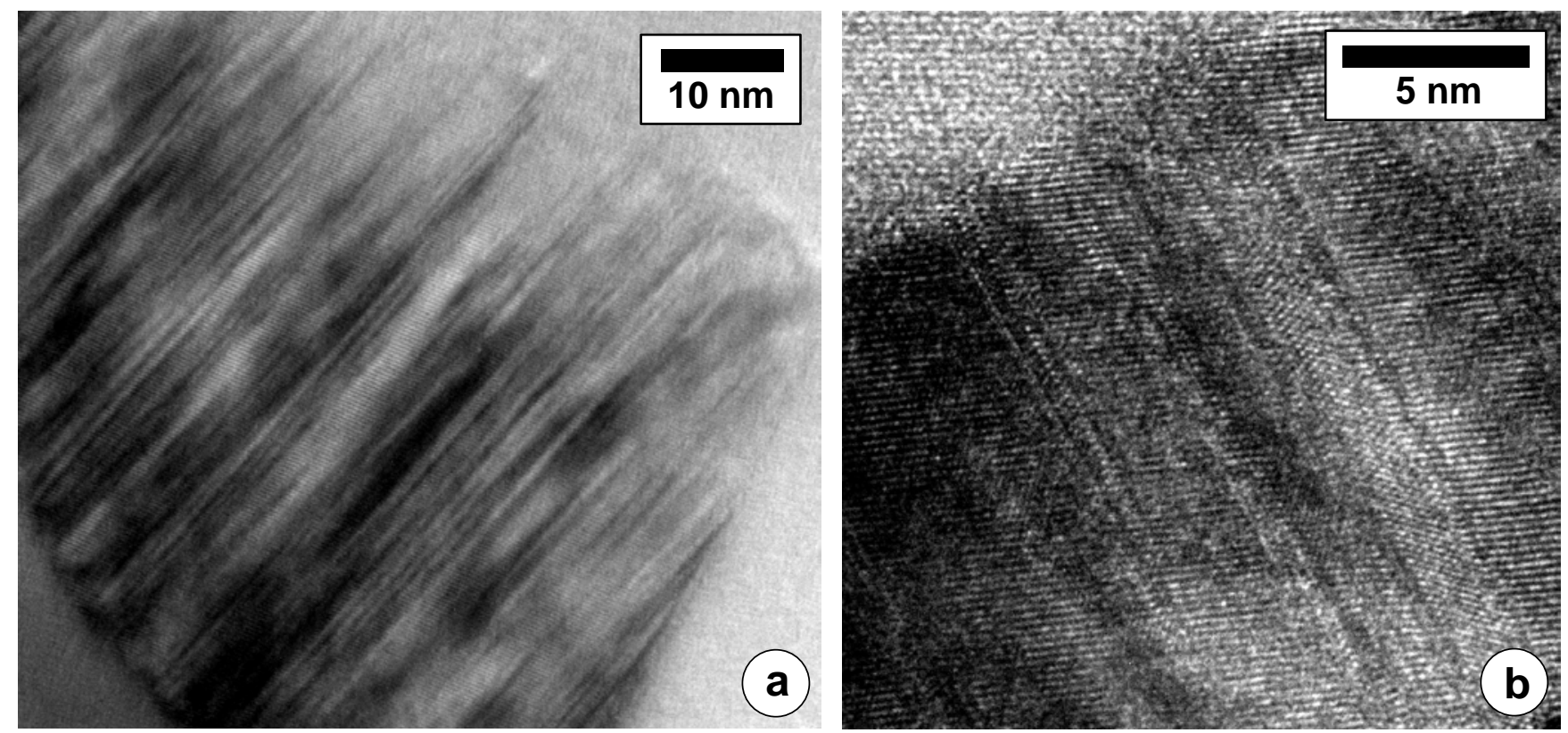

\section{rutile [111]}

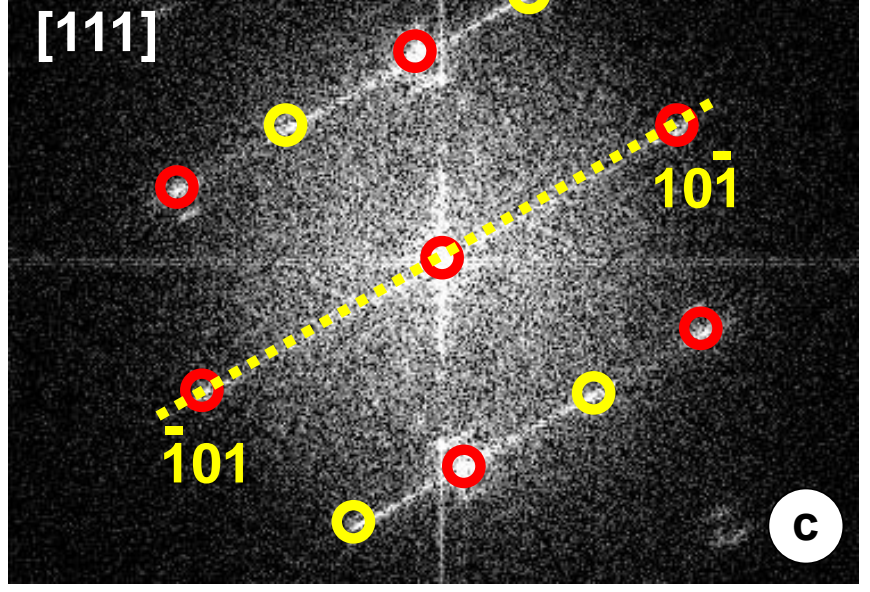

.

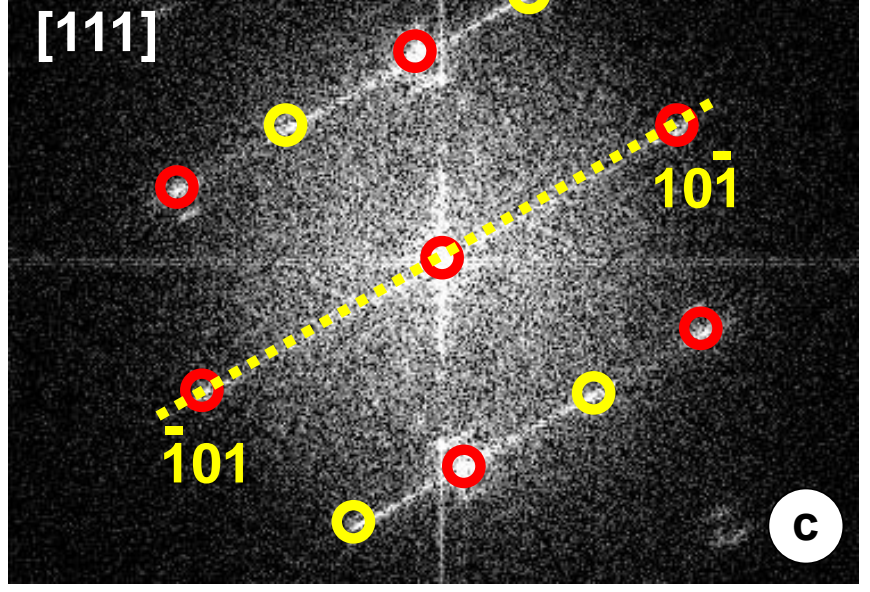

\section{(3)}

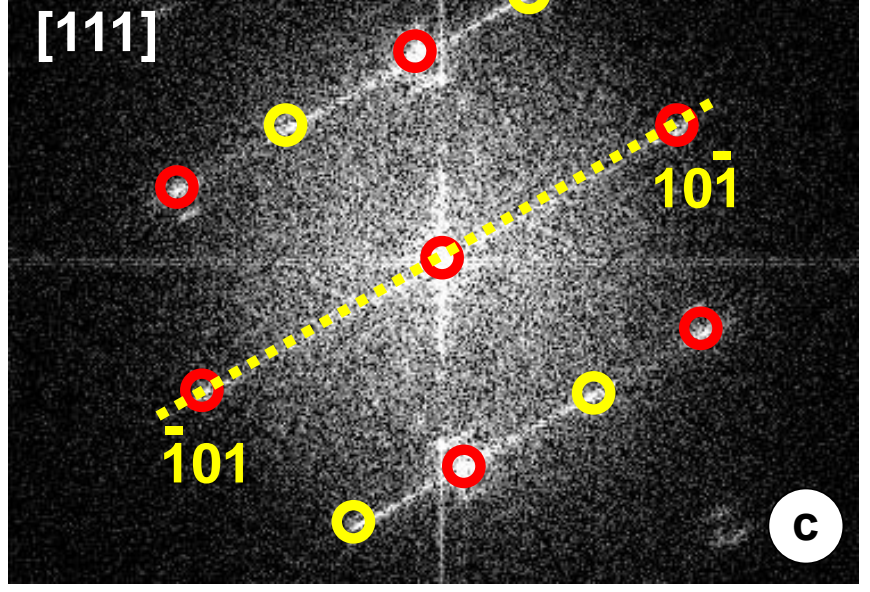

0

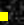

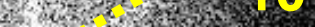

0 

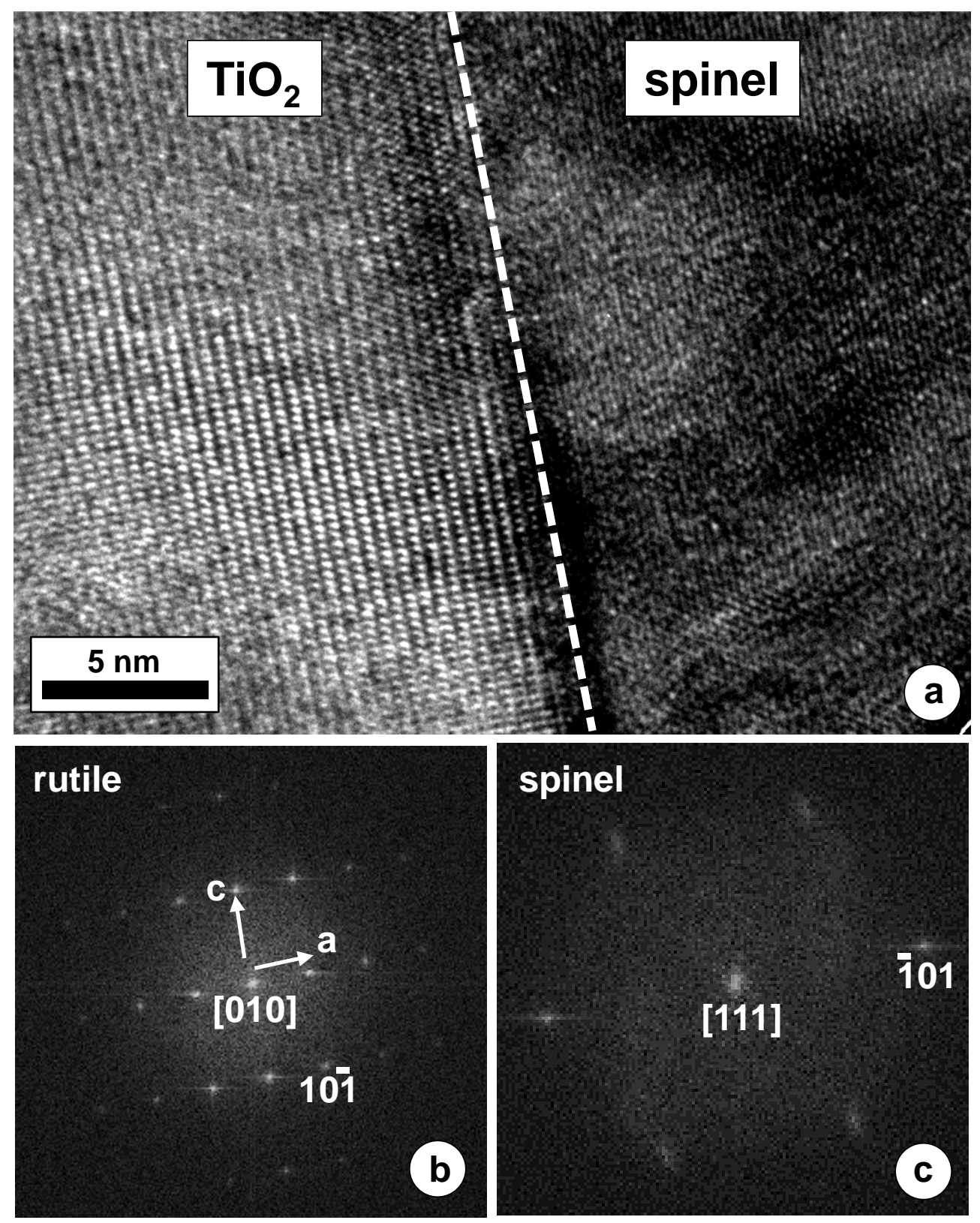


\section{Figure 13}

Stage 1: equilibrium condensation

Stage 2: aggregation and annealing
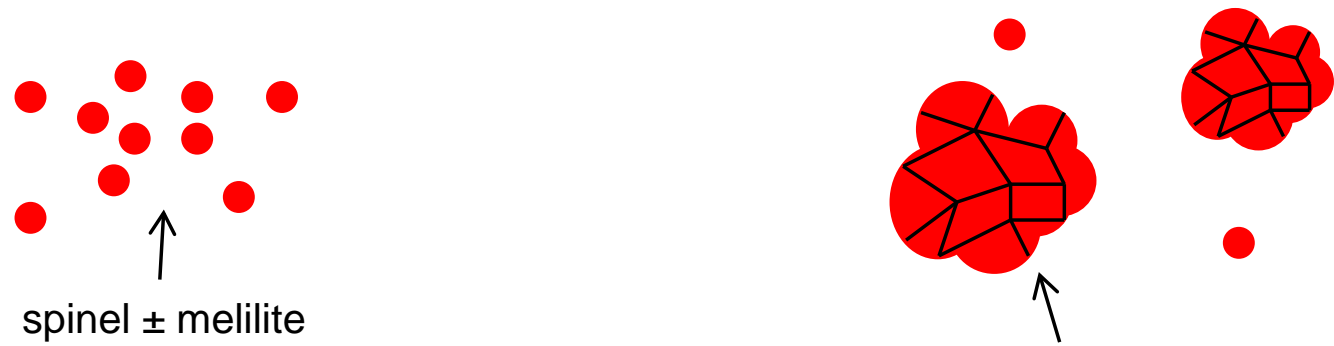

spinel \pm melilite

primary core materials

Stage 3: transport and injection

Stage 4: disequilibrium back-reaction with a gas

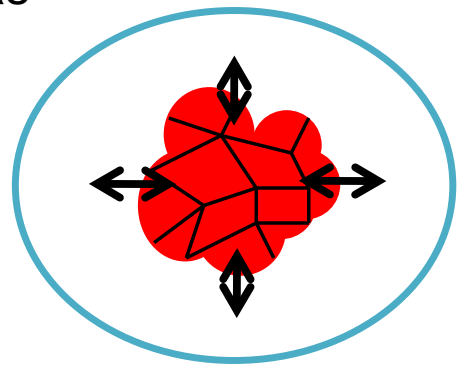

Stage 5: formation of Al-Ti-rich diopside

Stage 6: progressive decrease of $\mathrm{Al}$ and

in diopside

Al-Ti-diopside

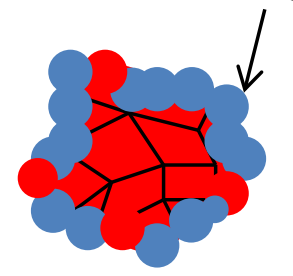

\section{Ti,Ca-saturated}

gas

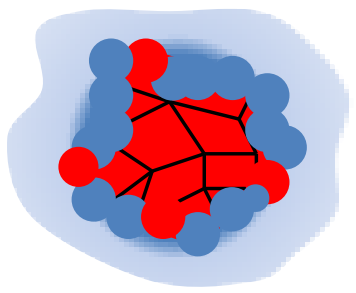

Stage 7: direct condensation of diopside

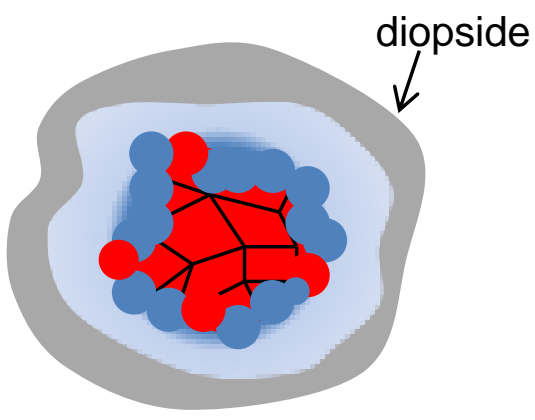

